\title{
The Impact of Relative Permeability on Horizontal Well Type Curve Analysis in Coalbed Methane Reservoirs
}

Kyle Remington Clark

West Virginia University

Follow this and additional works at: https://researchrepository.wvu.edu/etd

\section{Recommended Citation}

Clark, Kyle Remington, "The Impact of Relative Permeability on Horizontal Well Type Curve Analysis in Coalbed Methane Reservoirs" (2011). Graduate Theses, Dissertations, and Problem Reports. 2248. https://researchrepository.wvu.edu/etd/2248

This Thesis is protected by copyright and/or related rights. It has been brought to you by the The Research Repository @ WVU with permission from the rights-holder(s). You are free to use this Thesis in any way that is permitted by the copyright and related rights legislation that applies to your use. For other uses you must obtain permission from the rights-holder(s) directly, unless additional rights are indicated by a Creative Commons license in the record and/ or on the work itself. This Thesis has been accepted for inclusion in WVU Graduate Theses, Dissertations, and Problem Reports collection by an authorized administrator of The Research Repository @ WVU. For more information, please contact researchrepository@mail.wvu.edu. 
The Impact of Relative Permeability on Horizontal Well Type Curve Analysis in Coalbed Methane Reservoirs

\author{
Kyle Remington Clark
}

Thesis submitted to the College of Engineering and Mineral Resources

at West Virginia University In partial fulfillment of the requirements

For the degree of

\author{
Master of Science \\ In \\ Petroleum and Natural Gas Engineering
}

Khashayar Aminian, Ph. D., Chair

Samuel Ameri, M.S.

Gary Winn, Ph. D.

Department of Petroleum and Natural Gas Engineering

\author{
Morgantown, West Virginia \\ 2011
}

Keywords: Relative Permeability, Horizontal Wells, Coalbed Methane Reservoirs, Type Curves, Gas Production Prediction Copyright 2011 Kyle Remington Clark 


\begin{abstract}
The Impact of Relative Permeability on Horizontal Well Type Curve Analysis in Coalbed Methane Reservoirs
\end{abstract}

\title{
Kyle Remington Clark
}

Coalbed methane (CBM) production has become increasingly profitable in recent years. Production prediction and analysis is challenging in these reservoirs due to two-phase flow conditions. A CBM reservoir is classified as an unconventional gas reservoir due to its unique flow and storage characteristics. Software simulators are by far the best way to predict production performance in CBM reservoirs.

This study investigated the impact of relative permeability on production type curves of horizontal wells in CBM reservoirs. Both relative permeability to gas and water were analyzed using numerical models. The simulation model used for this study is Eclipse Office due to its capability of incorporating the unique flow and storage characteristics of CBM reservoirs. A set of production type curves were developed throughout the study to compare all results. After the type curves were analyzed, a correlation between the relative permeability exponents and the peak production rate was generated and verified. A range of parameters was chosen to use for each simulation model based on previous work in the area.

The water relative permeability exponent had significant impact on gas production up until the peak gas rate was reached. The gas relative permeability exponent only had minor impact on the gas production type curve up until the peak production rate was reached. The shape of the water production type curve seemed to only be affected when the gas relative permeability exponent became large. The well penetration ( $\mathrm{L} / \mathrm{Xe}$ ) also had a significant impact on the gas production type curve. 


\section{Acknowledgements}

I would like to thank Dr. Kashy Aminian for being my research advisor and graduate coordinator throughout the past two years. His guidance and assistance in completing this project is greatly appreciated.

I would also like to thank the other members of my committee. Sam Ameri, Professor and Chairman of the Petroleum and Natural Gas Engineering Department, has given me endless support and encouragement for the past two years. His wisdom and leadership is a wonderful asset. I thank Dr. Gary Winn for joining my committee with short notice. His professionalism, motivation, and enthusiasm as an educator has inspired me and will never be forgotten. I also thank all other professors here at West Virginia University that have given me the tools and skills needed to complete this project.

I would like to thank my Grandparents and other distant relatives for all their love and support throughout my entire life. I also thank my friends for their kindness and companionship.

Lastly, I thank my parents, Dan and Debby Clark. Their unconditional love and support throughout my life has given me encouragement and motivation to accomplish all of my goals. I am forever grateful for their support. 


\section{TABLE OF CONTENTS}

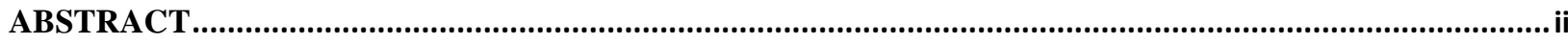

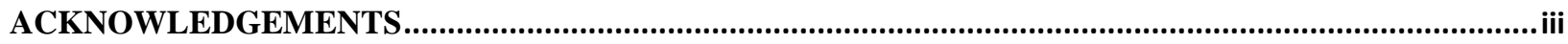

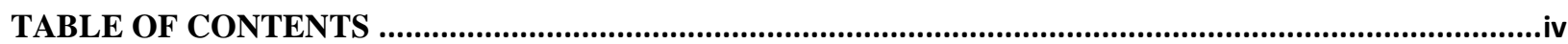

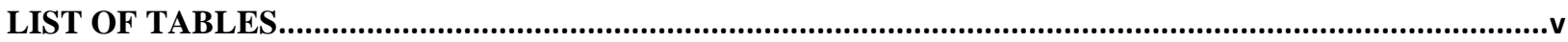

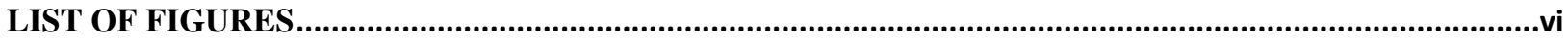

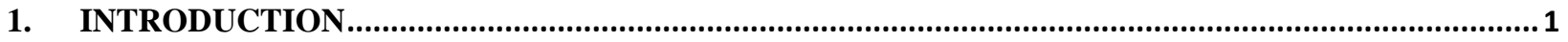

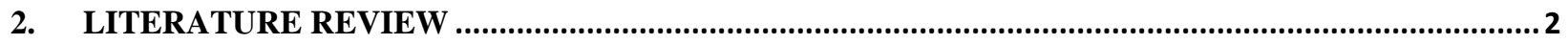

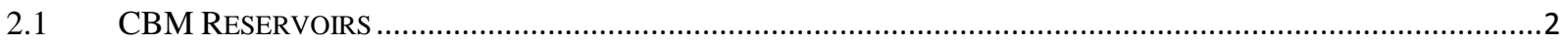

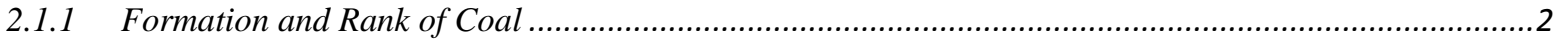

2.1.2 Porosity

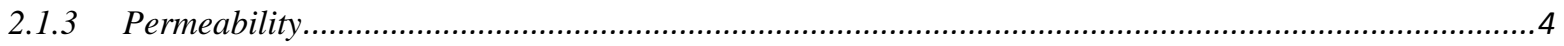

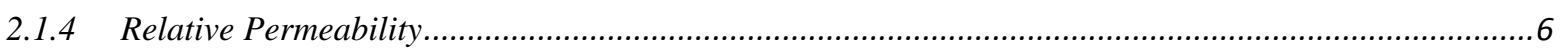

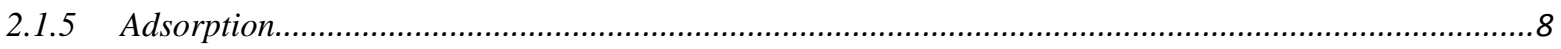

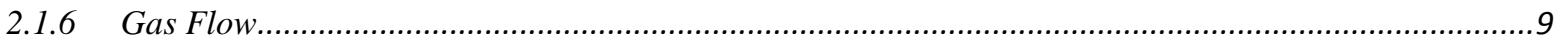

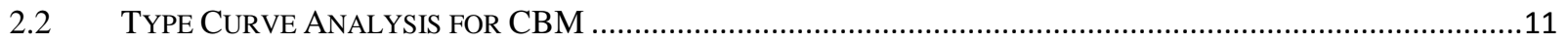

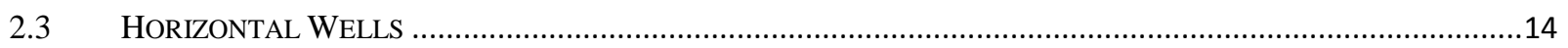

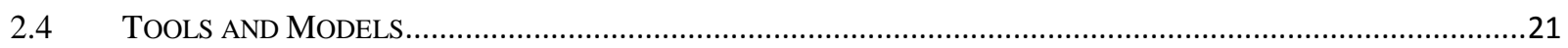

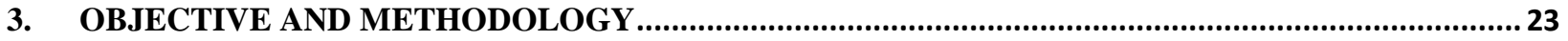

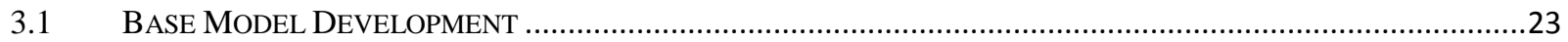

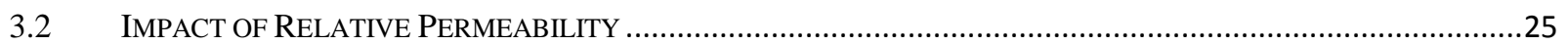

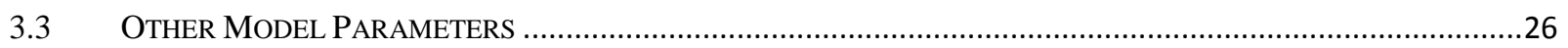

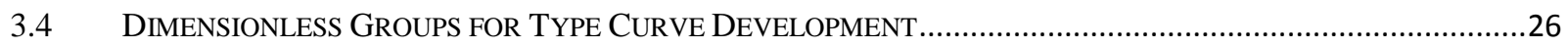

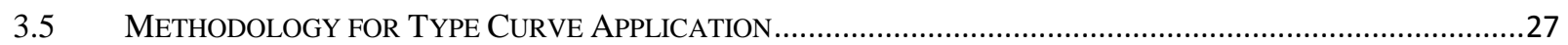

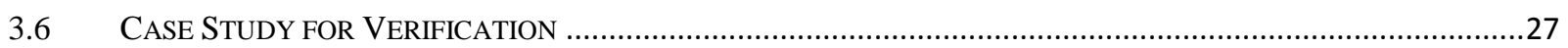

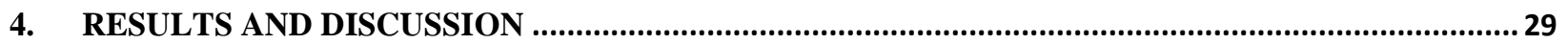

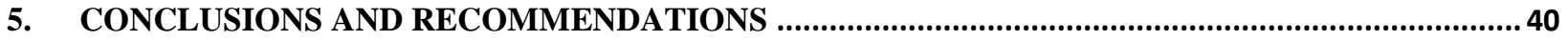

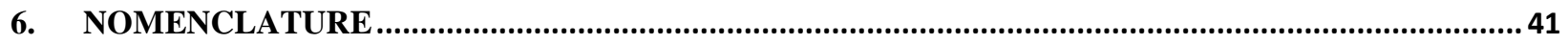

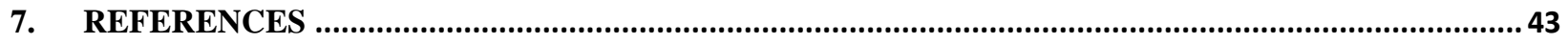




\section{List of Tables}

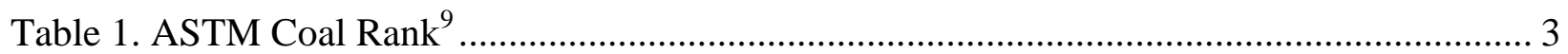

Table 2. Input Parameters for Base Model ......................................................................... 24

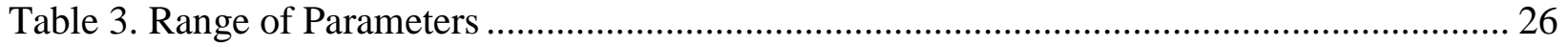

Table 4. Input Parameters for Case Study ...................................................................... 28 


\section{List of Figures}

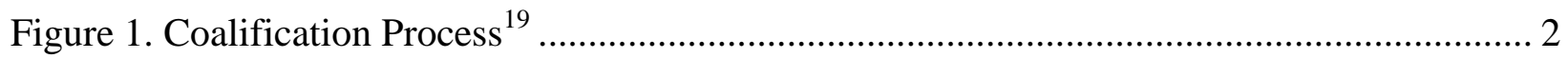

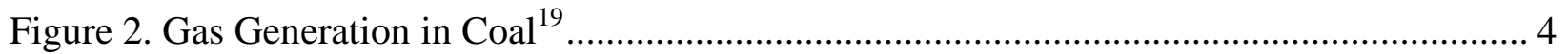

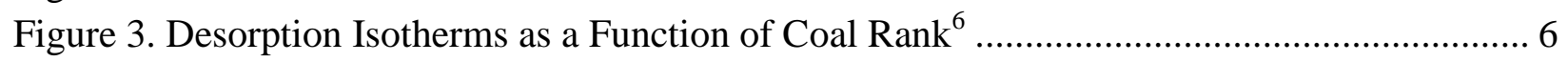

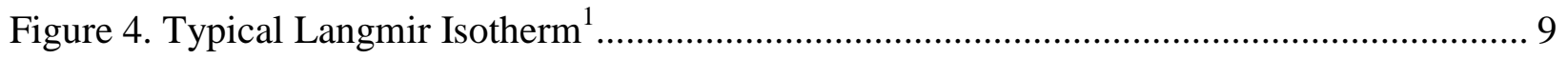

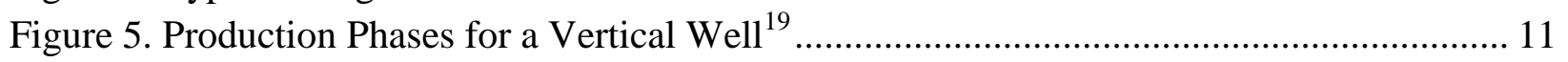

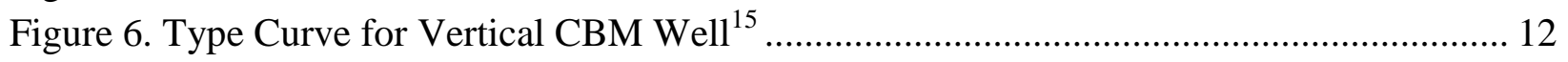

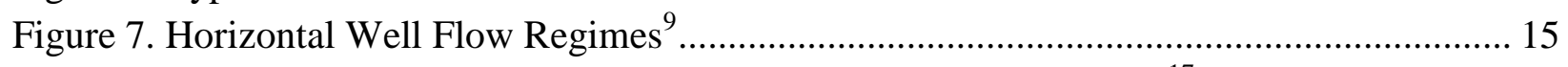

Figure 8. Effects of Horizontal Well Penetration on Production Behavior ${ }^{17}$............................... 17

Figure 9. Effects of Drainage Area Shape on Production Behavior ${ }^{17}$......................................... 17

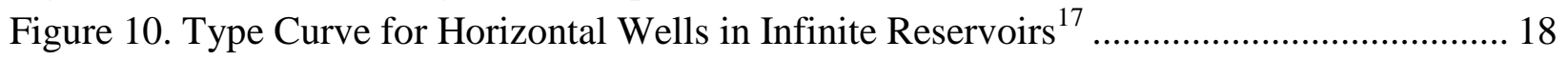

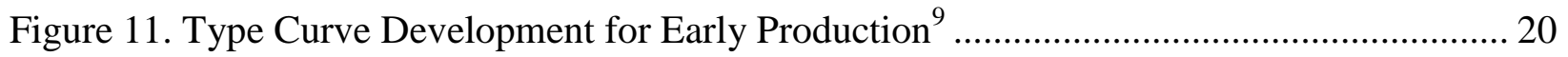

Figure 12. Type Curve Development for Late Production ${ }^{9}$......................................................... 20

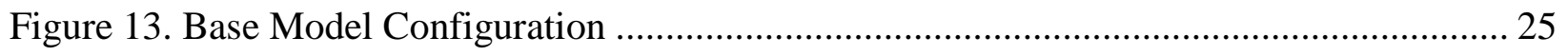

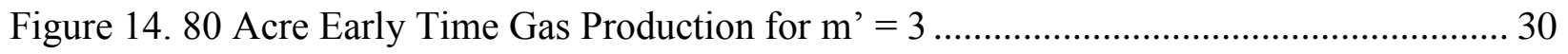

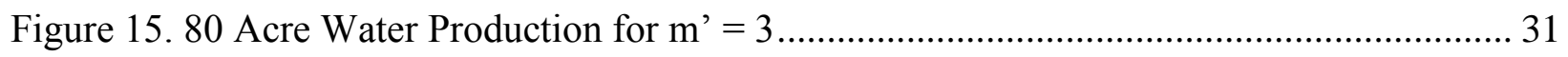

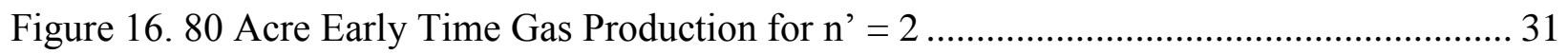

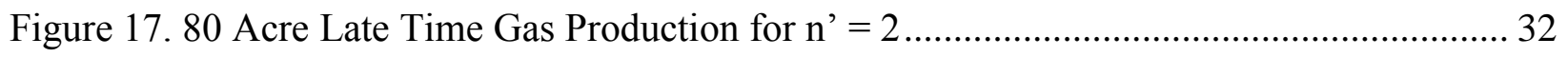

Figure 18. 80 Acre Water Production for n' = 2 …….......................................................... 32

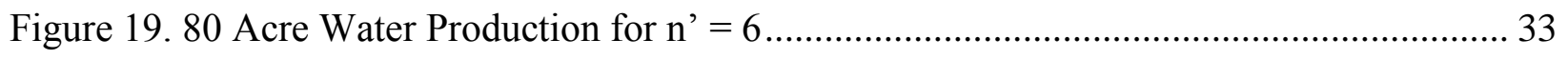

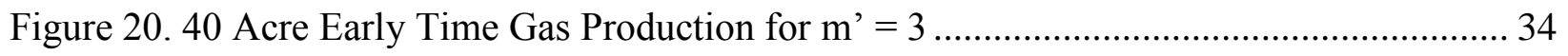

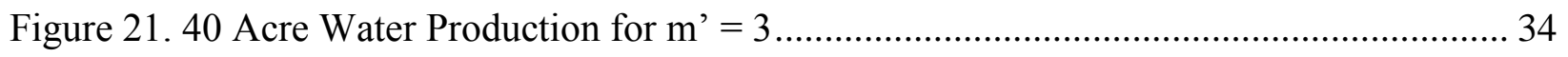

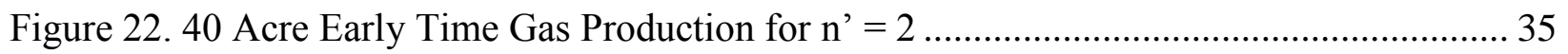

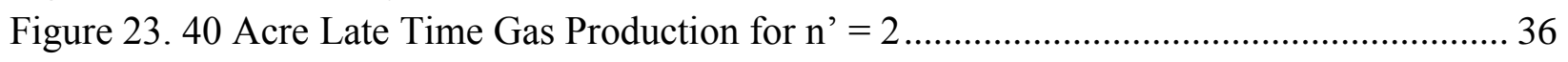

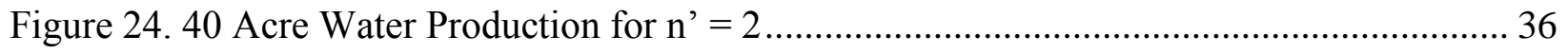

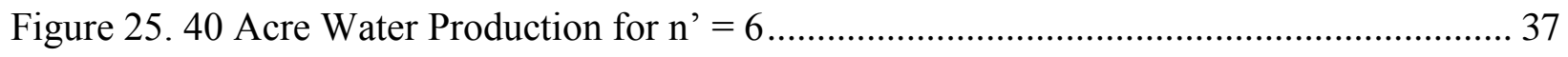

Figure 26. 80 Acre L/Xe Comparison Early Gas Curve for m' $=3$ ………………................... 38

Figure 27. 40 Acre L/Xe Comparison Early Gas Curve for $\mathrm{m}^{\prime}=3$ ……................................... 38

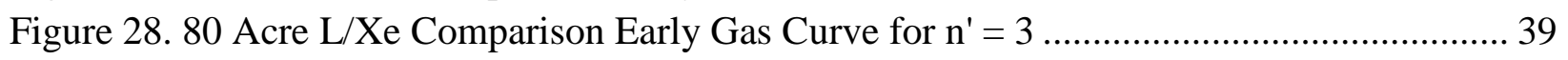




\section{INTRODUCTION}

Coalbed Methane (CBM) has transformed from a once considered unconventional gas play into a mainstream source of natural gas in the United States since the 1980's. The United States Energy Information Administration state CBM proved reserves have increased from 3.7 TCF in 1989 to 18.58 TCF in 2009. Currently CBM accounts for nearly 12 percent of the total estimated reserves and 9 percent of the annual natural gas production in the U.S. ${ }^{1}$ Recent U.S. estimates indicate greater than 700 trillion cubic feet (TCF) of coalbed methane gas in place with over $100 \mathrm{TCF}$ thought to be economically recoverable. ${ }^{3}$ The gas reserves and total production in the U.S. is expected to increase over the next several years as new reserves are discovered and more underdeveloped basins achieve substantially higher production. For this reason, it is important to develop reliable tools to help producers understand and evaluate the potential in CBM production.

Horizontal wells in coalbed methane reservoirs are far more beneficial than vertical wells. The most significant advantage is that the borehole can be directed with respect to the principle permeability arrangement of the coal seam. Using the natural fracture network in the coal seam increases the initial water production through the borehole. This higher rate of water flow at early times accelerates the gas production compared to a vertical well. Although a horizontal well can be much more productive in a CBM reservoir, an economical analysis should first be conducted before eliminating the option of drilling a vertical well.

During the two phase flow conditions of a CBM reservoir, the relative permeability relationships between gas and water control the flow of gas and water in the reservoir. Relative permeability data is very limited and nearly impossible to obtain from core samples. History matching is widely used to determine relative permeability. Thus it is important to study the impact of relative permeability characteristics of the coal being analyzed. This information can help predict production performance of a horizontal well and be made available for individual gas producers. 


\section{LITERATURE REVIEW}

\subsection{CBM Reservoirs}

Coalbed methane reservoirs differ from conventional reservoirs in several different ways. Unlike conventional reservoirs, coal is both the source rock and the reservoir rock. Also, the gas storage mechanism in coal is different in that the methane is not a free gas. Instead the gas is adsorbed into the coal matrix. Other ways CBM reservoirs differ from conventional include the natural fracture system, production performances, and mechanical properties.

\subsubsection{Formation and Rank of Coal}

The most abundant deposits of coal were formed more than 300 million years ago, in the time that dinosaurs, swamps, and gigantic plants and trees covered the earth. Coal begins as layers of plant matter accumulating at the bottom of a body of water. These plant deposits are submerged rapidly enough to be protected from biodegradation and oxidation. After time, layers of sand and mud covered the plant matter forming a soggy, sponge-like material called peat. Over several thousand years, the peat was buried beneath more silt and sand, compressing the peat under Earth's surface. As more time passed, the pressure and heat from the earth increased turning the peat into coal. This process is called coalification and is simplified in Figure 1.

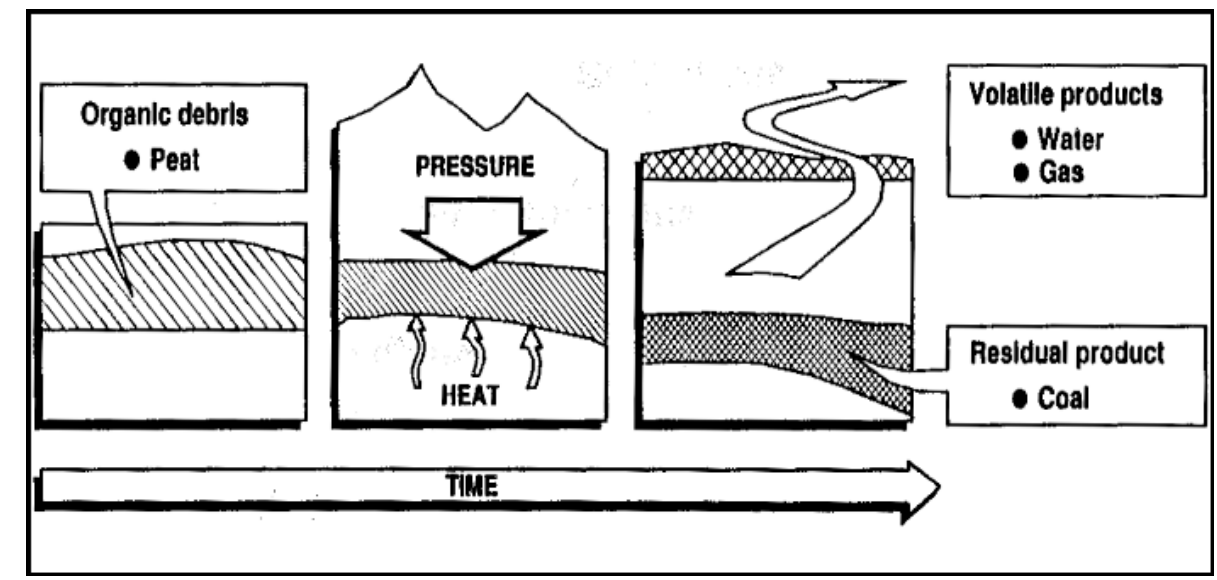

Figure 1. Coalification Process ${ }^{19}$

Through the coalification process, methane and other gases such as nitrogen and carbon dioxide are produced by geochemical alteration through heat and pressure. ${ }^{6}$ The thermally derived methane is stored in micropores in the coal while the moisture and volatiles escape 
during the peat formation. The micropores in the coal are able to store tremendous amounts of methane per unit of coal.

The amount of gas retained in the coal during the coalification process greatly depends on the coal quality or rank. Coal rank is most influenced by temperature, pressure, and length of burial. Typically coal rank increases with depth however this is not always true. As the coal matures, the physical and chemical properties of the coal change, thus distinguishing its rank. The rank can vary the coal's porosity, permeability, heating value, and other physical and mechanical properties.

The four levels of coal rank are lignite, sub-bituminous, bituminous, and anthracite. Within these four levels are thirteen sub-levels shown in Table 1. Bituminous coal is of the most interest for CBM drilling. In this rank of coal, retention capabilities have improved and more gas has been generated at this point of the coal maturation process. Physical and mechanical properties of the high volatile A bituminous through low volatile bituminous coals have the greatest potential for being a reservoir. Figure 2 shows the gas generation in coal.

Table 1. ASTM Coal Rank ${ }^{9}$

\begin{tabular}{|l|l|c|c|c|c|}
\hline \multirow{3}{*}{ Class } & \multirow{2}{*}{ Group } & \multicolumn{2}{|c|}{$\begin{array}{c}\text { Volatile Matter } \\
(\% \mathrm{dmmf})\end{array}$} & \multicolumn{2}{c|}{$\begin{array}{c}\text { Calorific Value } \\
\left(\mathrm{kcal} / \mathrm{kg} \mathrm{mmmf}^{*}\right)\end{array}$} \\
\cline { 3 - 6 } & & $\begin{array}{c}\text { Greater } \\
\text { than }\end{array}$ & $\begin{array}{c}\text { Equal or } \\
\text { less than }\end{array}$ & $\begin{array}{c}\text { Equal or } \\
\text { greater than }\end{array}$ & Less than \\
\hline \multirow{5}{*}{ Anthracite } & Meta- anthracite & - & 2 & - & - \\
& Anthracite & 2 & 8 & - & - \\
& Semi- anthracite & 8 & 14 & - & - \\
\hline \multirow{5}{*}{ Bituminous } & Low volatile & 14 & 22 & - & - \\
& Medium volatile & 22 & 31 & - & - \\
& High volatile A & 31 & - & 7778 & - \\
& High volatile B & - & - & 7222 & 7778 \\
& High volatile C & - & - & 6389 & 7222 \\
\hline \multirow{2}{*}{$\begin{array}{l}\text { Sub- } \\
\text { bituminous }\end{array}$} & Sub-bituminous A & - & - & 5833 & 6389 \\
& Sub-bituminous B & - & - & 5278 & 5833 \\
& Sub-bituminous C & - & - & 4611 & 5278 \\
\hline \multirow{2}{*}{ Lignite } & Lignite A & - & - & 3500 & 4611 \\
& Lignite B & - & - & - & 3500 \\
\hline
\end{tabular}




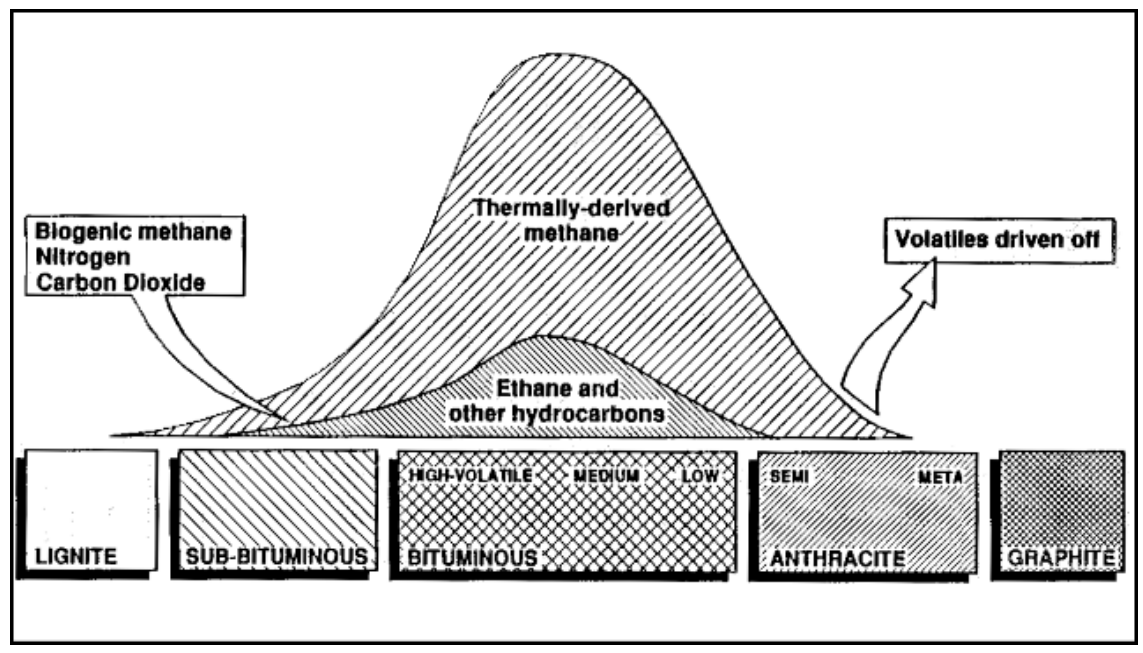

Figure 2. Gas Generation in Coal ${ }^{19}$

\subsubsection{Porosity}

Porosity is the percentage of void space in a rock formation and exists in coal as fracture porosity and matrix porosity, making coal a dual porosity reservoir. This study focuses only on a single porosity model. The size of pore spaces can vary from cleat fractures to intermolecular interstices ${ }^{6}$. Porosity tends to decrease with rank into the low-volatile bituminous stage, then increases as additional volatiles are lost and pore space is left open. Macropores are the void spaces in the cleat system and other natural fractures in the coal reservoir. These macropores are vital for gas and water transportation but have little effect on methane storage. Micropores are mainly where the hydrocarbons are stored in coal.

The porosity in coal is usually low, ranging from $0.1 \%$ up to $10 \%$. Despite the low porosity in $\mathrm{CBM}$ reservoirs, large volumes of gas can be stored in the micropores. The gas storage capacity in the micropores can be equivalent to that of a $20 \%$ porosity sandstone with $100 \%$ gas saturation at the same depth. ${ }^{10}$

\subsubsection{Permeability}

Permeability is the most significant parameter in evaluating a CBM reservoir because it controls reservoir performance. Permeability is the formation property that relates pressure drop and flow rate through the formation. ${ }^{6}$ Permeability varies as a function of the direction of flow in coal seams. This means the fracture system is anisotropic with two horizontal permeability components and one vertical component. The horizontal components are $\mathrm{k}_{\mathrm{x}}$ and $\mathrm{k}_{\mathrm{y}}$ which 
correspond to the face cleats and butt cleats in the coal seam. The vertical component is $\mathrm{k}_{\mathrm{v}}$. Although permeability is so critical, it is the most difficult parameter to evaluate accurately. This is because the frequency of the natural fracture, interconnections, degree of fissure (cracks), aperture direction of butt and face cleats, water saturation, depth and in-situ stress all has an effect on permeability. ${ }^{11}$

When producing from a CBM reservoir, a two phase flow regime is present in the interconnected cleat network. Effective and absolute permeability take place in order to separate or distinguish between the two phase flow through the porous media. Schlumberger defines effective permeability as "the ability to preferentially flow or transmit a particular fluid when other immiscible fluids are present in the reservoir." In other words, effective permeability is the ability of gas flow in a gas-water reservoir. The relative saturations of the fluids as well as the nature of the reservoir affect the effective permeability. Absolute permeability is defined by Schlumberger as "the measurement of the permeability conducted when a single fluid or phase is present in the rock." Permeability is measured in units of darcies or millidarcies. As previously mentioned, depth of the coal affects the permeability. The Langmuir isotherms of coal suggest that for most coal seams, the quantity of gas is primarily a function of coal quality, which improves with depth. Therefore, as the depth of the coal seam increases, the amount of adsorbed gas also increases non-linearly. ${ }^{6}$ This is illustrated in Figure 3.

For development of coalbed methane, important natural fracture attributes (cleats) contribute to permeability pathways for gas and water flow to wells. These cleats are divided into face cleats and butt cleats. Although there are small amounts of free gas existing in the cleats, coalbed methane is mainly adsorbed on the large internal surface area of the impermeable coal matrix and fracture surfaces. Releasing the adsorbed methane is achieved by lowering the reservoir pressure through water production. As the coal seam is dewatered, the hydrostatic pressure on the seam is decreased, releasing the adsorbed gas. After desorption from the coal, the gas must diffuse through the coal matrix until it reaches the face and butt cleats. The cleats are conduits for gas and water flow to the wellbore. An increase in the number of cleats per unit volume of coal improves the permeability. Cleat aperture opening and length of the cleat also impacts the permeability. 


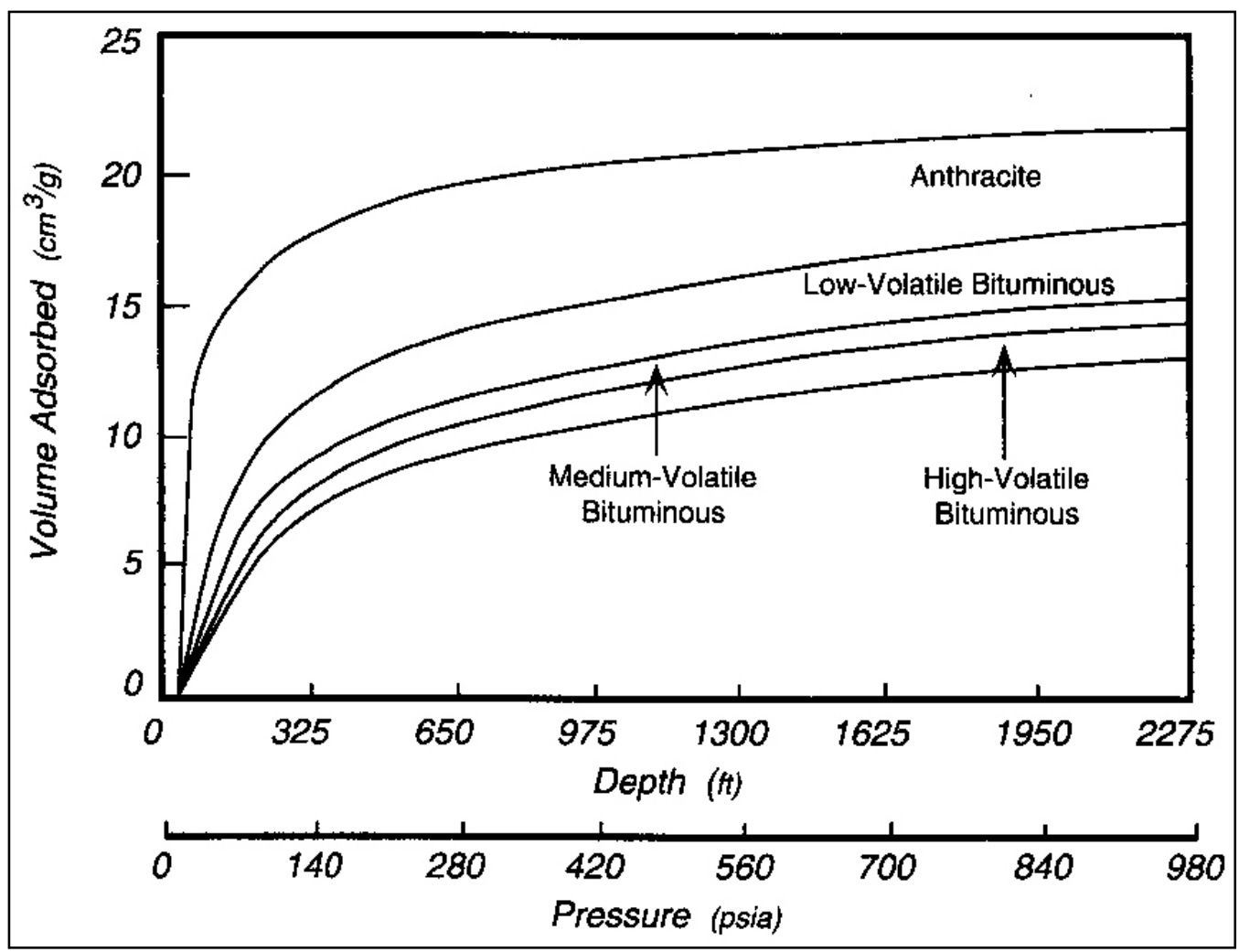

Figure 3. Desorption Isotherms as a Function of Coal Rank ${ }^{6}$

The orientation of the cleat system in coal is dependent upon stress fields, coal rank, and organic matter content. Typically low-volatile bituminous coal has the most developed network of cleats. The orientation of the cleats greatly impacts the direction of drilling and well location and spacing. Ideally, a horizontal well should be drilled perpendicular to the face cleat. This allows for maximum exposure to the natural fractures of the coal, increasing the gas production significantly. Experiments show that in shallow Appalachian Pennsylvanian coal beds, horizontal boreholes drilled perpendicular to face cleats yield 2 to 10 times the production rate of gas as holes drilled parallel to face cleats. ${ }^{12}$

\subsubsection{Relative Permeability}

Gas and water flow rates through the reservoir are proportional to the effective permeability to each of the phases. As mentioned before, effective permeability of a phase is the permeability that can be calculated using the flow rate and pressure drop of the given phase. Relative permeability is the ratio of the effective permeability to a base permeability. This is defined in Equation 2.1. ${ }^{6}$ 


$$
k_{r i}=\frac{k_{i}}{k_{b}} .
$$

It is important to understand which base permeability is used in order to normalize the effective permeability data. The same base permeability should be used for both gas and water effective permeability. This study uses the absolute permeability at a wetting phase saturation of $100 \%$ because of the natural fracture systems in coal have been assumed to be fully water saturated.

Relative permeability is a function of fluid saturation. In absence of measured data, a set of equations have been used to estimate the gas and water relative permeability as an adequate first approximation. ${ }^{6}$

$$
\begin{aligned}
& k_{r g}=k^{\prime} 1-S_{w}^{*} n^{\prime} \\
& k_{r w}=S_{w}^{*} m^{\prime} \ldots \ldots \ldots
\end{aligned}
$$

In equations 2.2 and $2.3, \mathrm{k}^{\prime}$ is the gas relative permeability coefficient, n' is the gas relative permeability exponent and $\mathrm{m}^{\prime}$ is the water relative permeability exponent. $\mathrm{S}_{\mathrm{w}}{ }^{*}$ is the normalized water saturation of the reservoir and is defined in Equation 2.4.

$$
S_{w}^{*}=\frac{S_{w}-S_{i w}}{1-S_{i w}}
$$

In equation 2.4, $\mathrm{S}_{\mathrm{w}}$ is the water saturation and $\mathrm{S}_{\mathrm{iw}}$ is the irreducible water saturation.

An analysis of published relative permeability data indicates that the gas relative permeability exponent $\left(n^{\prime}\right)$ is typically about 1.5 and the water relative permeability exponent $\left(m^{\prime}\right)$ is approximately $3{ }^{6}$ Actual relative permeability behaviors will differ from that estimated from equations 2.2 and 2.3. However these equations can be used as a reasonable first approximation in reservoir simulation studies. The exponents $n^{\prime}$ and $m^{\prime}$ in equation 2.2 and 2.3 are called Corey Gas Factor and Corey Water Factor, respectively.

Despite the significance of relative permeability on CBM production, actual recorded measurements are limited. This is because proficient core samples with well developed cleat 
systems are impossible to obtain because the coal strength reaches a minimum where cleating is most developed. ${ }^{1}$ As a result, relative permeability and other fracture system properties are determined by well testing or history matching. If production history has not been initiated or the history production is limited, the relative permeability must be assumed.

\subsubsection{Adsorption}

One of the major characteristics that make coal reservoirs unique is the manner in which the gas is stored. In conventional reservoirs, the gas exists in a free state in the pores of the reservoir rock. In contrast, the majority of methane in coal reservoirs exists in a near liquid state in the micropores of the coal matrix due to physical sorption. Although there is some free gas that exists in the natural fractures of the coal seam, the adsorbed gas in the micropores accounts for over $95 \%$ of the total gas content. ${ }^{12}$

Most hydrocarbon gases in coal seams are retained by physical adsorption to the coal molecular structure. Proportionately more of Ethane and other heavier hydrocarbons are more strongly adsorbed because they are less mobile then methane. Physical adsorption is caused by weak attractive forces that exist between pairs of molecules or atoms. Adsorption of methane to coal is caused by such weak physical forces. Adsorption increases non-linearly with pressure and is reversible by increasing the temperature or decreasing the pressure. ${ }^{6}$ The adsorption mechanics creates the inconsistency of high gas storage capacity in a reservoir rock with porosity less than $2.5 \%{ }^{20}$ As the reservoir water is produced, the hydrostatic pressure decreases, allowing the gas to be released from the micropores. The pressure at the time the gas releases from the coal is called the critical desorption pressure $\left(\mathrm{P}_{\mathrm{c}}\right)$.

As a result of adsorption in the coal matrix, the relationship between the gas storage capacity of a coal to pressure is defined by the desorption isotherm and not by the real gas law. ${ }^{13}$ The Langmuir equation, Equation 2.5, is universally used in the industry because of its close fit of adsorption data of methane on all coals. As the pressure in a coal seam increases with depth, the coal storage capacity of adsorbed gas also improves. A typical Langmuir isotherm is shown in Figure 4. 


$$
G_{C}=\frac{V_{L} P}{P_{L}+P}
$$

$\mathrm{G}_{\mathrm{c}}=$ Gas Content (Scf/ton)

$\mathrm{V}_{\mathrm{L}}=$ Langmuir volume constant (Scf/ton)

$\mathrm{P}_{\mathrm{L}}=$ Langmuir pressure constant (psia)

$\mathrm{P}=$ pressure $(\mathrm{psia})$

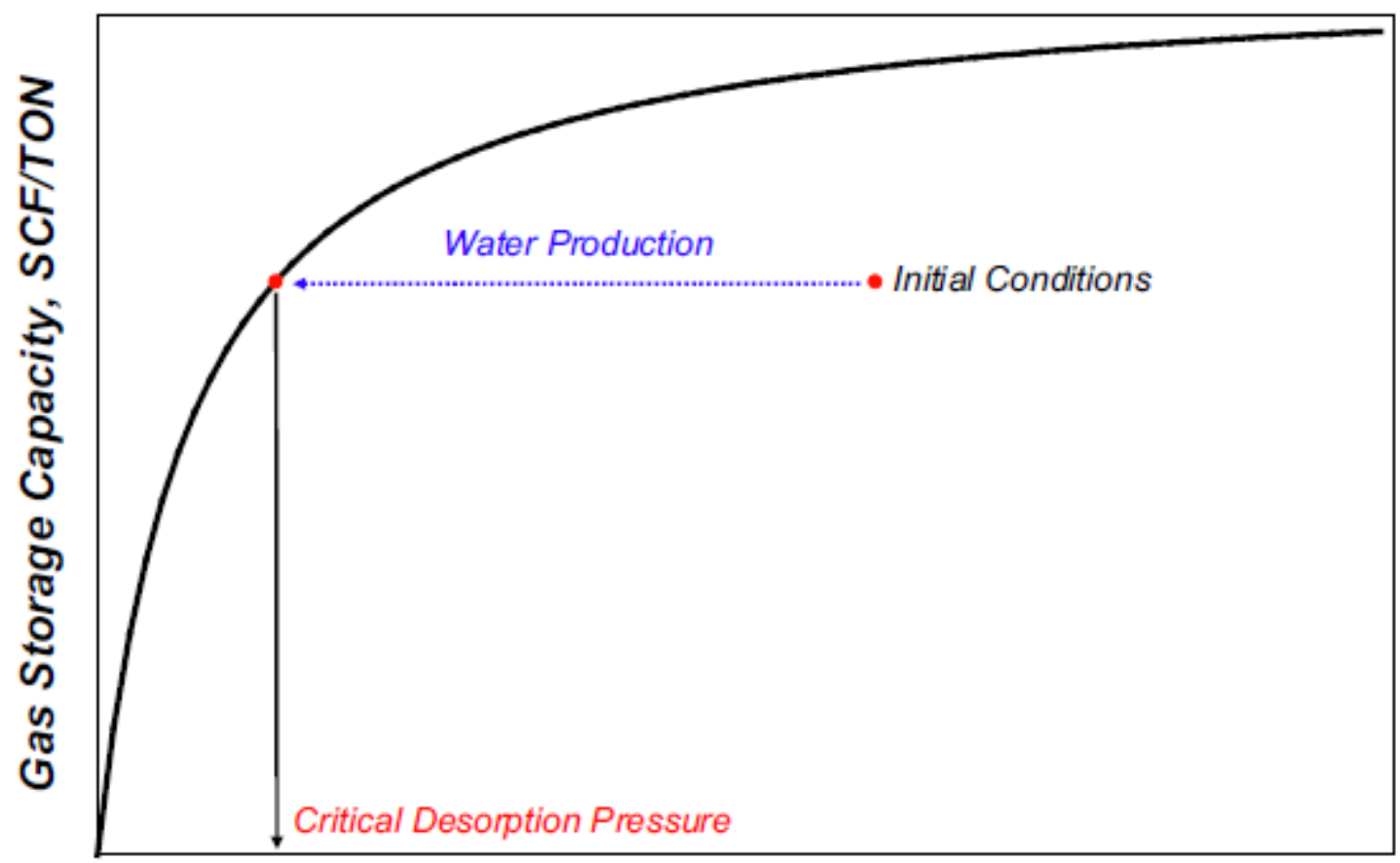

Pressure, psia

Figure 4. Typical Langmir Isotherm ${ }^{1}$

\subsubsection{Gas Flow}

The gas flow mechanisms from the formation to the wellbore in CBM reservoirs greatly differ from that of conventional reservoirs. Due to the low permeability of the coal matrix, most fluid flow to the wellbore occurs through the coal cleats. Without significant amounts of natural fracturing, gas could not be produced in commercial quantities. ${ }^{6}$ The coal cleats also account for storage space for the reservoir fluids. Most of the water produced from a CBM well originates from the natural fracture system. 
The production rates in commercial CBM reservoirs are dominated by gas flow from the coal matrix into the natural fracture system. This process is controlled by diffusion which is driven by methane concentration gradients across the micropores as the driving force. As the gas diffuses through the micropores of the coal matrix into the coal cleats, the gas will flow according to Darcy's law as in a conventional reservoir where the mass transport depends upon a pressure gradient. $^{20}$

There are three phases of gas and water production in a CBM reservoir. Before drilling begins, the coal cleats will be fully water saturated. In terms of the Langmuir isotherm, the cleats are under saturated with respect to gas. As previously discussed, some water must be produced to lower the pressure and initiate the desorption process to allow for gas production. The first phase of production will have a constant water production with little or no gas. As the water is produced, the bottom hole flowing pressure will decrease and ultimately reach its minimum value by the end of the phase. The time period required for the pressure disturbance to reach the boundary in Phase I is called infinite acting.

During Phase II, the water will continue to produce with time. As enough time passes, a two-phase flow regime will be established near the wellbore. Early in this two-phase flow regime, gas flow is followed by pressure drops deeper within the coal seam as more water is produced. During this time, an increase in the gas relative permeability will increase the gas production rate. Similarly, a decrease in the water relative permeability will decrease the water production rate. In the case of a rectangular drainage area, as soon as the disturbance is created, the well will see the closest boundary first. After reaching the second boundary, the well will start the depletion state. The time period where the well has seen the first boundary, but not yet the second is called the transition region or transition time. ${ }^{14}$

The final stage of production from a CBM reservoir, Phase III, is where both boundaries are reached and the well has stabilized, having little change in relative permeability. After this point the well is producing in a pseudo-steady state. The gas rate has peaked by this phase and will continue to follow a typical decline. There can still be water production during Phase III although it is very low or even considered negligible. A summary of gas and water flow is illustrated in Figure 5 below. 


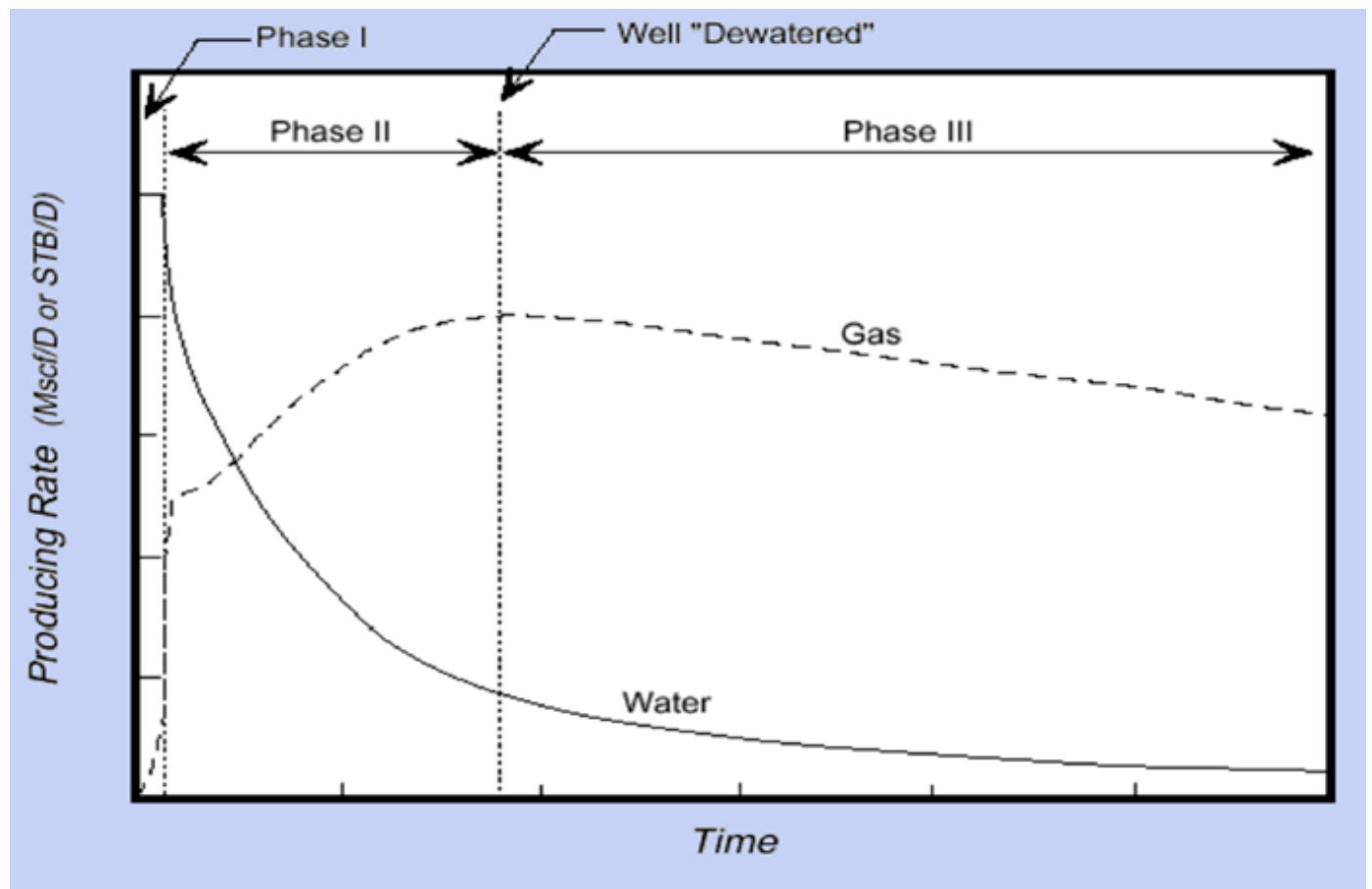

Figure 5. Production Phases for a Vertical Well ${ }^{19}$

\subsection{Type Curve Analysis for CBM}

A type curve is a very simple but yet reliable engineering tool used during preliminary well evaluations. It can be used for production history matching as well as a simple and quick way of predicting gas and water rates for evaluation of a prospect well. In order to perform history matching with a type curve, production history data must be available. When this data is not present, the reservoir parameters must either be calculated or assumed. If the reservoir parameters are already established, a type curve can be used to predict the production performance of the well. Type curves are not meant to replace reservoir engineering calculations. Instead, they provide the operators with a reasonable estimation of the production data throughout the life of a given well.

Previous research and development has been performed on type curves for vertical CBM wells and for horizontal and vertical unconventional wells. In order to develop a type curve, the production histories must be converted to dimensionless values of rate and time. These parameters are then presented in a log-log scale plot. Using the dimensionless groups of 
reservoir parameters eliminate the effects of variance in gas and water rates, time, and reservoir area. An example of a type curve for a vertical CBM well is shown in Figure 6.

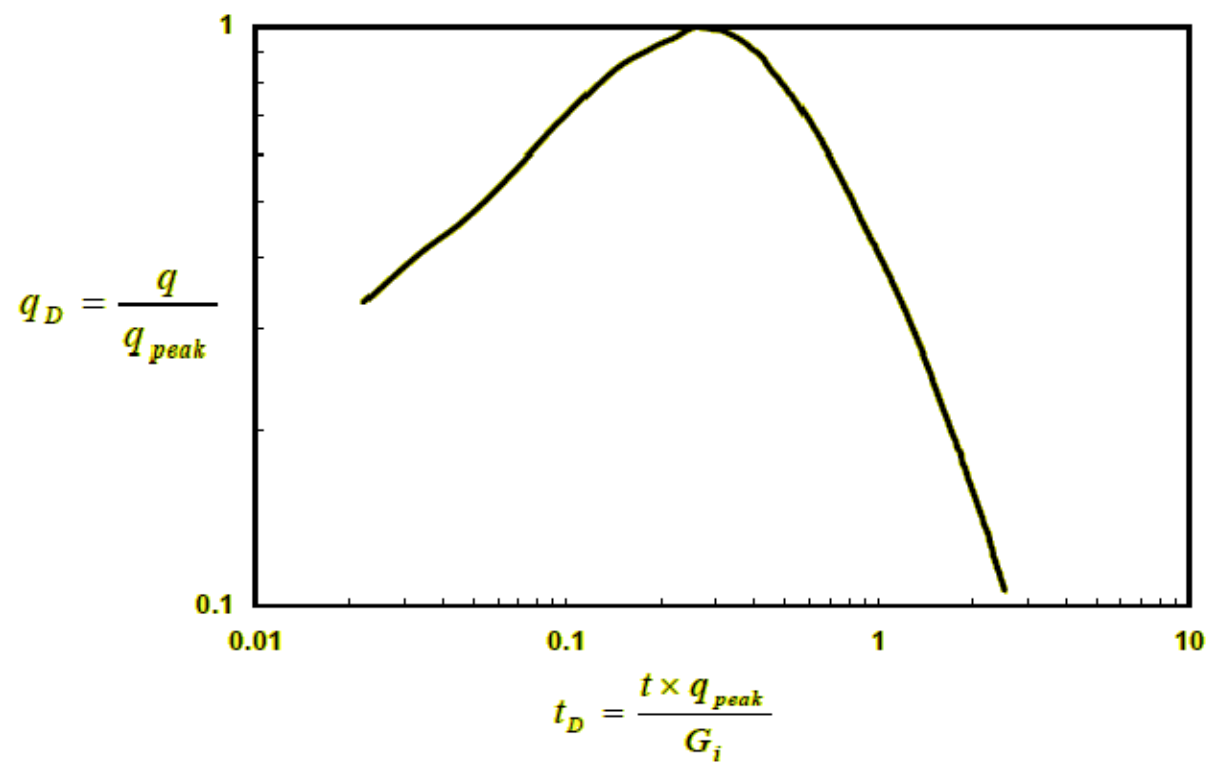

Figure 6. Type Curve for Vertical CBM Well ${ }^{15}$

In order to develop type curves, two set of dimensionless rate and time were defined for gas and water. The first set of dimensionless groups investigated were gas related. The following equations have been used in predicting the performance of vertical CBM wells in previous studies $^{15}$ :

$$
\begin{aligned}
& t_{g D}=\frac{q_{\text {peak }} g}{G_{i}} t \\
& q_{g D}=\frac{q_{g}}{q_{\text {peak }} g}
\end{aligned}
$$

In equations 2.6 and $2.7, \mathrm{q}_{\mathrm{g}}$ is the gas production rate, $\left(\mathrm{q}_{\text {peak }}\right)_{\mathrm{g}}$ represents the maximum or peak gas rate and $\mathrm{G}_{\mathrm{i}}$ is the initial gas in place. The initial gas in place can be calculated from the following equation.

$$
G_{i}=43560 A h G_{c}
$$


In equation 2.8, the coal bulk density is not included as usual. This is because the simulation model used in this study requires different units. Normally $G_{i}$ would appear in units of Scf, however the Eclipse modeling program asks for units of Mscf. Therefore in this calculation, the coal bulk density is included in $\mathrm{G}_{\mathrm{c}}$.

The second set of dimensionless groups investigated were water related and as follows:

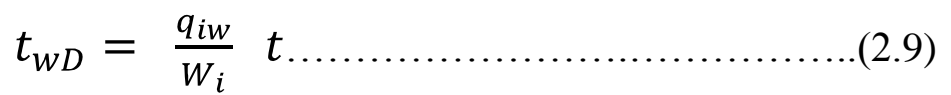

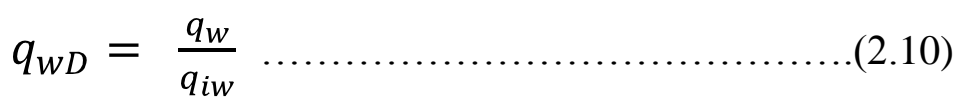

In equation 2.9 and $2.10, \mathrm{q}_{\mathrm{iw}}$ represents the initial (maximum) water production rate and $\mathrm{W}_{\mathrm{i}}$ is the initial water in the natural fracture system. $\mathrm{W}_{\mathrm{i}}$ can be calculated using the following equation:

$$
W_{i}=43560 A h \varphi_{f} S_{w i}
$$

In equation $2.11, \varphi_{f}$ is the cleat system porosity and $S_{\mathrm{wi}}$ represents the initial cleat system water saturation. The previous equations were used to present the dimensionless groups of data into a log-log scale plot.

Type curves can also be used as a quick and simple engineering tool to predict the gas and water production rates for evaluation of a well. To do this, $\left(\mathrm{q}_{\mathrm{peak}}\right)_{\mathrm{g}}$ and $\mathrm{G}_{\mathrm{i}}$ must be estimated for gas production predictions. The parameters $\mathrm{q}_{\mathrm{iw}}$ and $\mathrm{W}_{\mathrm{i}}$ must be evaluated from available formation properties. Equations 2.8 and 2.11 can be used to calculate $\mathrm{G}_{\mathrm{i}}$ and $\mathrm{W}_{\mathrm{i}}$, respectively. The initial water production rate can be estimated from the single-phase liquid unsteady state solution since the coal cleats are assumed to be fully water saturated initially. However, the peak gas production rate is more difficult to estimate because of the two phase flow conditions of a CBM reservoir. To overcome this problem, the variations of $\left(\mathrm{q}_{\text {peak }}\right)_{\mathrm{g}}$ with various parameters was investigated to develop a simplified correlation, starting with a dimensionless group for $\left(\mathrm{q}_{\text {peak }}\right)_{\mathrm{g} .}{ }^{15}$ The dimensionless peak gas rate for vertical wells is defined in Equation 2.12.

$$
q_{\text {peak }}{ }_{g D}=q_{\text {peak }} * \frac{1422 T \mu_{c} z_{c}}{k h\left(P_{c}{ }^{2}-P_{w f}{ }^{2}\right)} \quad \ln \frac{r_{e}}{r_{w}}-\frac{3}{4}+s
$$


In Equation 2.12, $\mathrm{p}_{\mathrm{c}}$ is the critical gas desorption pressure. This is the pressure at which gas desorption from the coal matrix into the cleat system begins. The critical gas desorption pressure can be determined from the point on the Langmuir isotherm that corresponds to the initial gas content. The gas viscosity and z-factor should be determined at the critical desorption pressure. Using this dimensionless group minimizes the impact of permeability, thickness, and drainage area. ${ }^{15}$

\subsection{Horizontal Wells}

Directional drilling, also referred to as horizontal drilling, is defined by Schlumberger as "the science of deviating a wellbore along a planned path to a target located a given lateral distance and direction from vertical." ${ }^{7}$ A horizontal well starts like a conventional vertical well and at a predetermined "kick-off" point (KOP), the well is directed toward the target reservoir entering the formation roughly parallel to the bedding plane. The technology used to employ this technique dates back to 1891, when the first patent was granted for equipment to place a horizontal hole from a vertical well. Since the mid 1980s, there have been dramatic advances in this technology making horizontal drilling much more efficient and profitable. ${ }^{8}$

While there are significant advantages in horizontal drilling over conventional vertical drilling, there are also disadvantages that must be carefully examined before adopting the method. The principle benefit of horizontal drilling in CBM reservoirs is the ability to intersect the coal seam perpendicular to the principle permeability directions. By doing this, the natural fractures in the face cleats of the coal allow for increased gas flow to the wellbore. Other advantages of horizontal drilling include increased drainage area, expanded accessibility in difficult to reach reservoirs, less rig moves and surface area disturbance, and improved safety precautions through the ability of drilling relief wells.

The most significant disadvantage of drilling horizontally is cost. When drilling a vertical well, gravity plays an important role of contributing to the downward force needed to penetrate the rock. In horizontal wells, the same gravity becomes an unfriendly factor that technology must overcome. The equipment used to create the force needed to drive the drill bit horizontally can be costly. Also, performing adjustments or repair work in horizontal wells is more difficult, requiring more expensive equipment to be mobilized to push tools down the hole. 
Wellbore storage also becomes a problem in CBM reservoirs due to the more complex nature of the transient.

There are three horizontal well flow regimes in CBM reservoirs after wellbore storage is stabilized. The first is radial flow in a vertical plane toward the well. This flow regime is called early-time pseudo-radial because permeability anisotropy causes an elliptical flow pattern. Linear flow then follows in the second flow regime. This begins when the transient reaches the upper and lower boundaries of the reservoir. Gas flows linearly toward the wellbore within the horizontal plane. The third flow regime is called late-time pseudo-radial flow. This happens as the transient becomes so far from the wellbore that flow once again becomes radial. These flow regimes are illustrated in Figure 7.

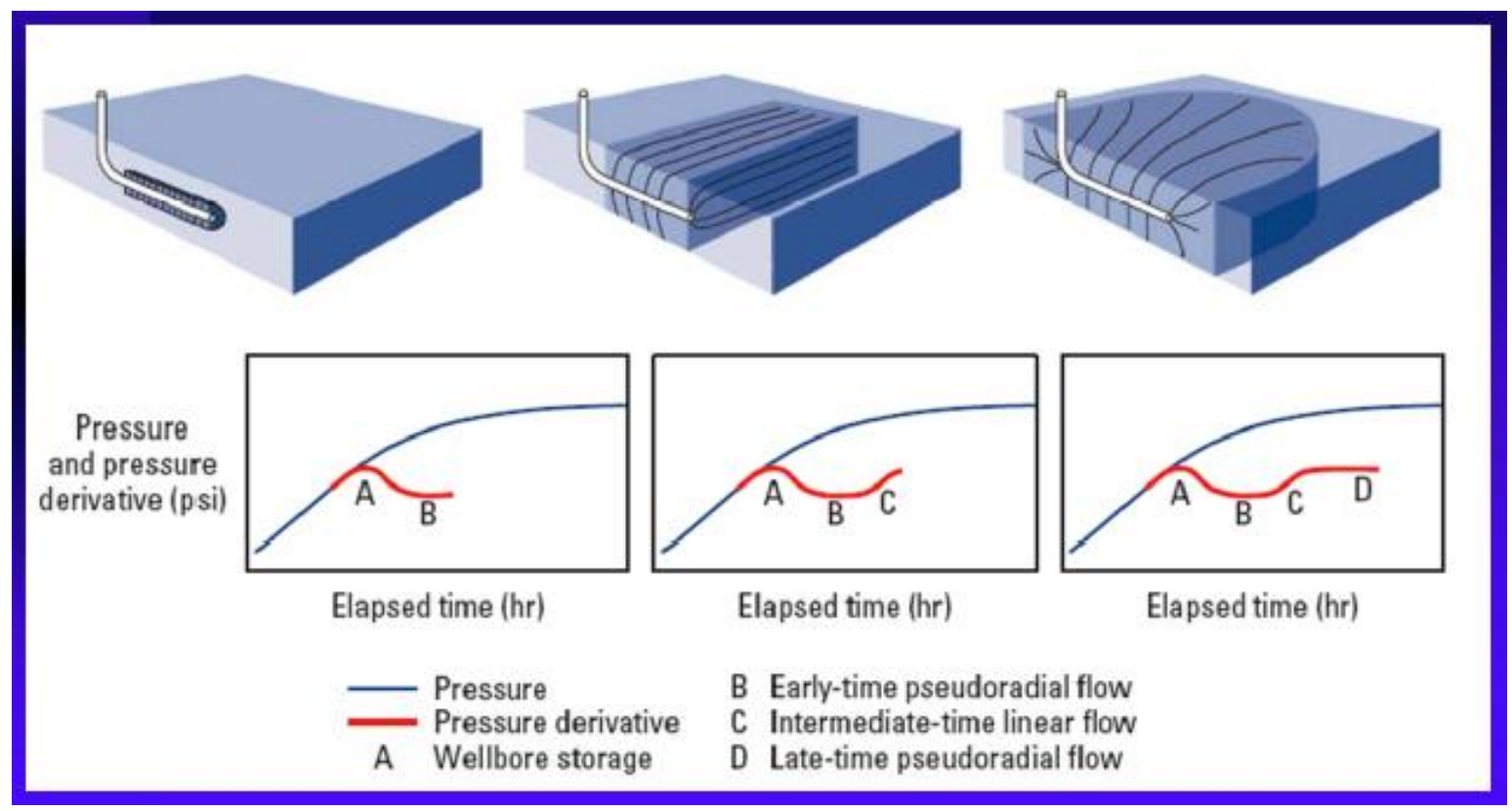

Figure 7. Horizontal Well Flow Regimes ${ }^{9}$

For horizontal wells, in addition to the side boundaries of the areal drainage plane, the top and bottom reservoir boundaries also influence well productivity. Thus, a horizontal well shape factor depends upon ${ }^{14}$ :

1. Drainage area shape

2. Well penetration

3. Dimensionless well length 
There has been previous research in developing type curves for predicting horizontal well production. The dimensionless groups investigated in these type curves were for an unconventional finite and infinite reservoir. The dimensionless cumulative production and dimensionless time definitions based on drainage area are as follows:

$$
\begin{gathered}
t_{D A}=\frac{0.001055 k_{H}}{\varphi c_{t} \mu A} t \ldots \ldots \\
G_{p D \text { area }}=\frac{36 T}{h \varphi c_{t} A P_{p}} G_{p}
\end{gathered}
$$

In Equation 2.13 and 2.14, the dimensionless cumulative production and time was based on well drainage area. Figure 8 below illustrates the effect of horizontal well penetration on long term production behavior of the well. Figure 9 below compares the performance of a horizontal well in a square drainage area versus a rectangular drainage area when the direction of the well coincides with the longer side of the rectangle. The drainage area for a horizontal well approaches an elliptical shape. As a result, the performance of the horizontal well in a rectangular drainage area is improved over a square drainage area. ${ }^{17}$

In Equation 2.15 and 2.16, the dimensionless cumulative gas production and time was based on well lateral length.

$$
\begin{aligned}
& t_{D L}=\frac{0.001055 k_{H}}{\varphi c_{t} \mu L^{2}} t \ldots \ldots \ldots \ldots \ldots \ldots \ldots \ldots \ldots \ldots \\
& G_{p D \text { length }}=\frac{36 T}{h \varphi c_{t} L^{2} P_{p}} G_{p} \ldots \ldots \ldots \ldots .
\end{aligned}
$$

Horizontal well production type curves can be effectively grouped by two dimensionless terms, the dimensionless wellbore radius $\left(\mathrm{r}_{\mathrm{wD}}\right)$ and the dimensionless well length $\left(\mathrm{L}_{\mathrm{D}}\right)$. The definitions of these two dimensionless terms are given below ${ }^{17}$ :

$$
\begin{aligned}
& L_{D}=\frac{L}{2 h} \frac{k_{v}}{k_{H}} \\
& r_{w D}=\frac{2 r_{w}}{L} \ldots
\end{aligned}
$$




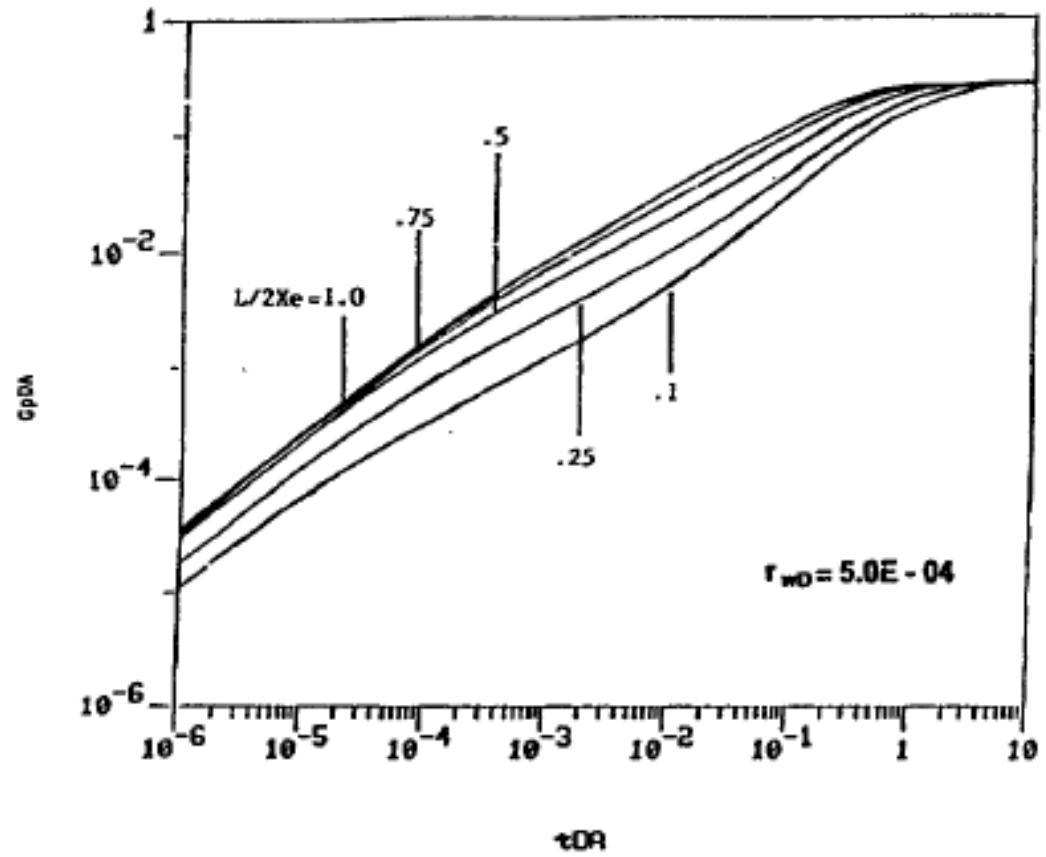

Figure 8. Effects of Horizontal Well Penetration on Production Behavior ${ }^{17}$

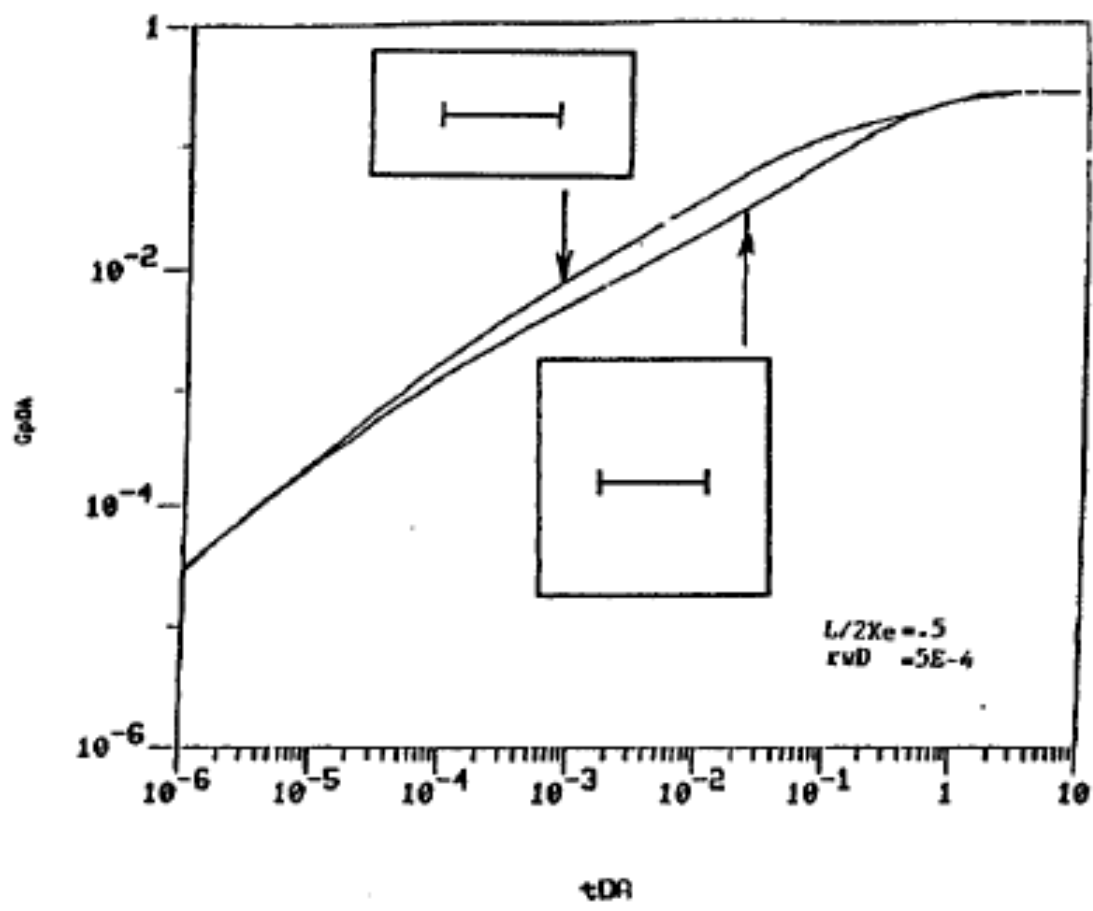

Figure 9. Effects of Drainage Area Shape on Production Behavior ${ }^{17}$

Figure 10 below illustrates a type curve for infinite reservoirs. This type curve is dependent on dimensionless well lateral length. When the lateral length of horizontal well is 
moderately long, $\mathrm{L}_{\mathrm{D}}>10$, the influence of the top and bottom boundaries becomes small and performance of a horizontal well approaches that of a fully penetrating infinite-conductivity fracture. ${ }^{14}$

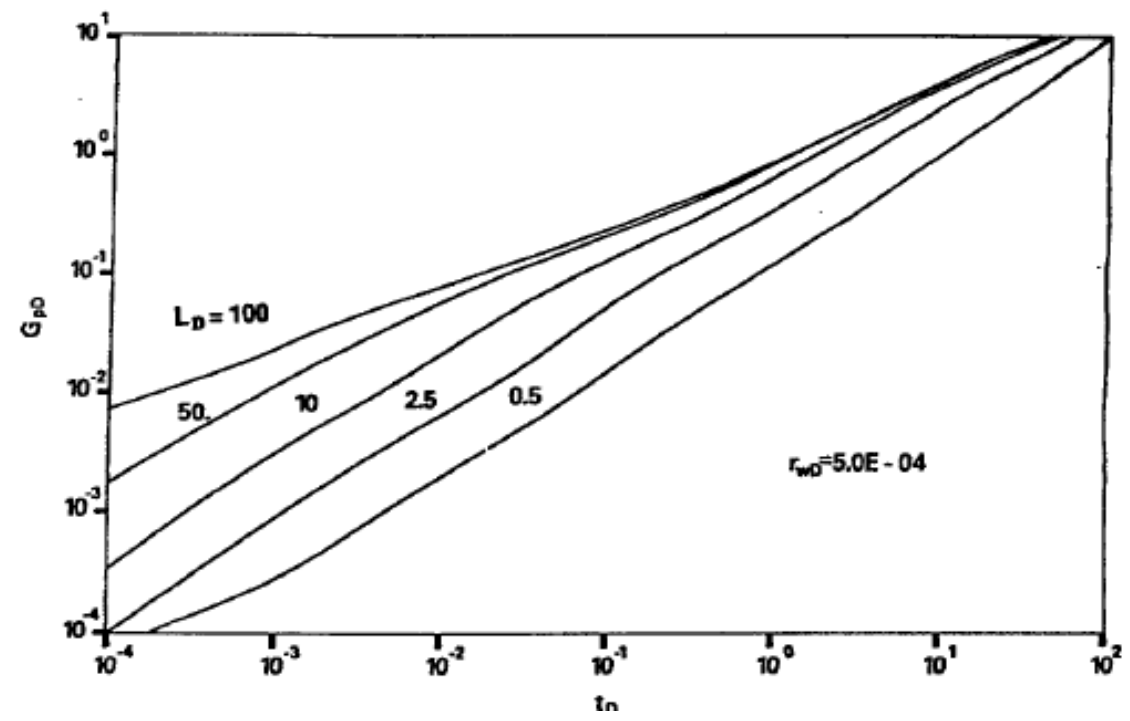

Figure 10. Type Curve for Horizontal Wells in Infinite Reservoirs ${ }^{17}$

Previous research of type curves in horizontal wells in CBM reservoirs done by Dylan Drinkard in 2009 prove that two different dimensionless groups must be used to distinguish between early and late time production. This is because horizontal wells have different flow regimes from vertical wells. In order to separate the linear flow from the radial flow, different dimensionless groups were investigated. After evaluating the different groups, Drinkard concluded that there was a need to have two different sets of unique type curves; one for early time linear flow and the other for late time radial flow. This is a result of the two flow regimes that a horizontal well in a CBM reservoir encounters during production. ${ }^{9}$

Drinkard investigated the dimensionless groups shown in Equations 2.13 through 2.16 to develop unique sets of type curves for horizontal wells in CBM reservoirs. After evaluating the results, Drinkard verified that there was a need for two different sets of unique type curves to account for the early and late flow of the horizontal well.

The first dimensionless group represents the early time linear flow of the CBM reservoir. This flow regime is present up until the peak gas production rate is reached. Originally, there 
was not a unique type curve to match the production during the linear flow phase. To correct this, Drinkard developed a different dimensionless group by multiplying $\mathrm{t}_{\mathrm{gD}}$ (Equation 2.6) by $\mathrm{L}_{\mathrm{D}}$ (Equation 2.17). This study uses the same dimensionless groups to compare the early time linear flow of the well. The production is dependent on the length of the well when it is in the linear flow regime. Regardless of the reservoir area, if the lateral length or L/Xe ratio are the same, the type curves match for the linear phase only. This is show in Figure 11.

The second dimensionless group developed by Drinkard represents the late time elliptical/radial flow regime of the horizontal well in a CBM reservoir. This flow regime is present after the peak production rate until the end of the well's life. Drinkard concluded that the best fit for the type curves for this flow regime was from previous research for vertical CBM production predictions. This unique match is because the horizontal well flow is similar to that of a vertical well. Equations 2.6 and 2.7 represent the best type curve for the late time radial flow regime. This is illustrated in Figure 12. 


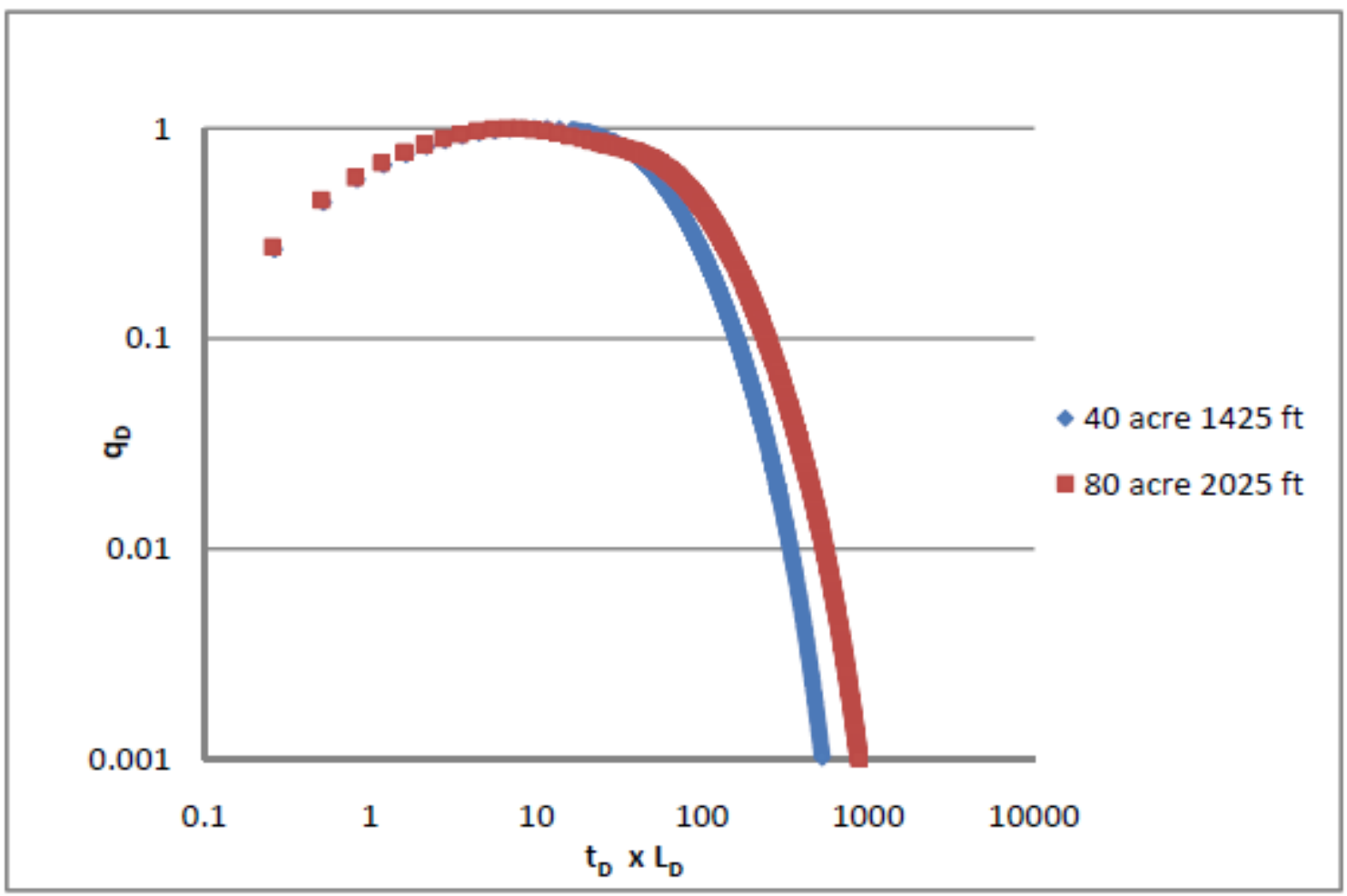

Figure 11. Type Curve Development for Early Production ${ }^{9}$

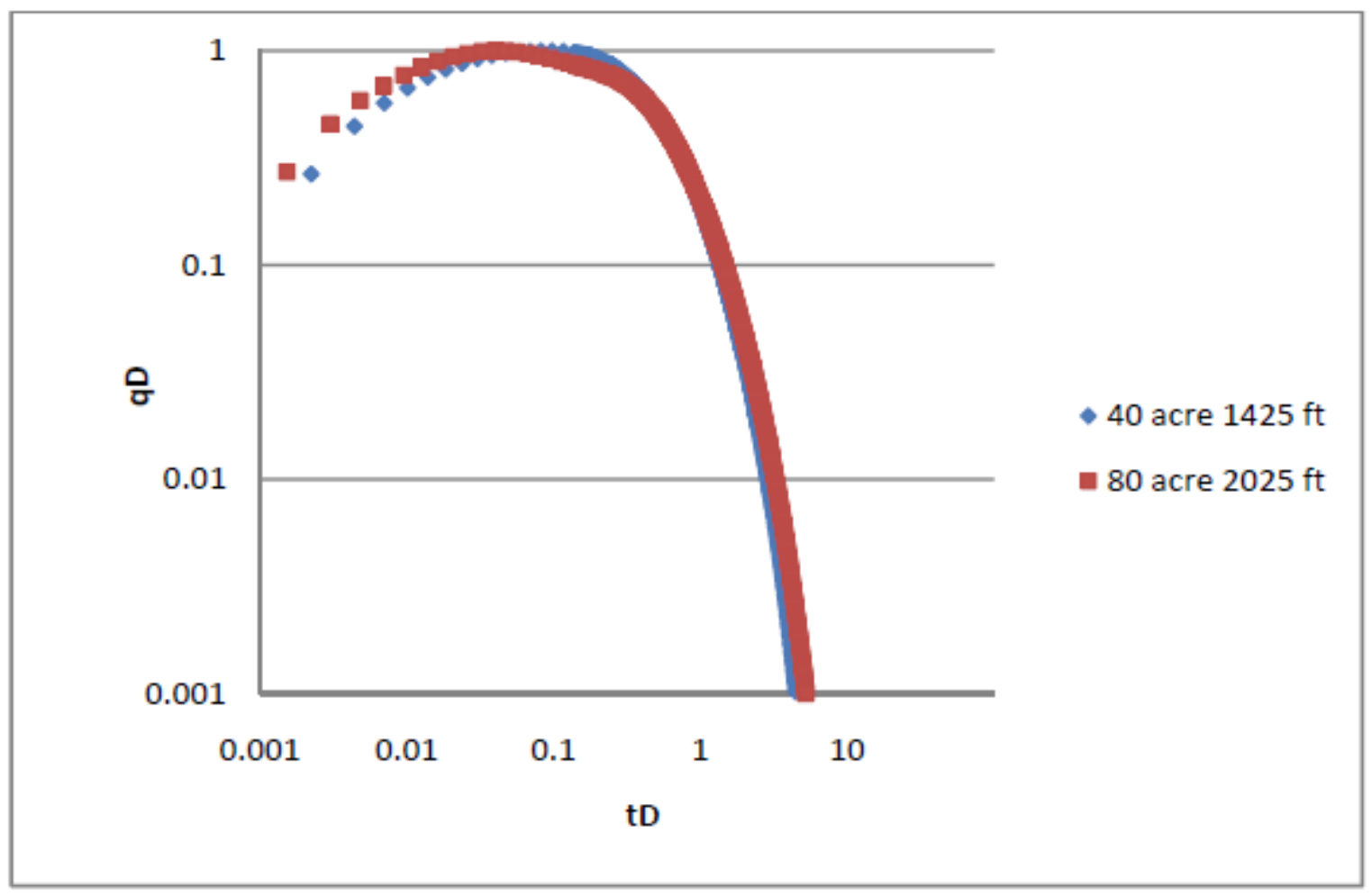

Figure 12. Type Curve Development for Late Production ${ }^{9}$ 


\subsection{Tools and Models}

Conventional production decline curves are typically used to forecast such things as recovery factor, future revenues, and well performance. Due to the complex nature of CBM production behavior, the conventional decline curve methods cannot be applied to these reservoirs to predict the production. Unlike conventional reservoirs, gas production from coal seams is controlled by a complex interaction of gas desorption from the coal matrix and twophase flow mechanics of gas and water through the cleat system. The performance of CBM reservoirs can best be predicted by numerical reservoir simulators that account for various mechanisms that control CBM production. Often, the number of variables needed for evaluation of a given prospect is more than those typically measured. Therefore, parametric studies must be conducted to evaluate the impacts of variation in reservoir properties. ${ }^{2}$

Before running the simulation, an explicit literature review was performed to identify the range of parameters to be used to generate the base model. Monte Carlo simulations allow one to evaluate the impacts of reservoir parameters on recovery factor, well performance and future revenue evaluation. When one or more of the key parameters are not available, it is necessary to perform Monte Carlo simulation to establish a reliable estimate of production potential and to evaluate the risk. Monte Carlo methods, also called Monte Carlo experiments, are a class of computational algorithms that rely on repeated random sampling to compute their results. These methods are most suited to calculation by a computer because of the repeated computations and random number selecting. However, it is time consuming and cumbersome to conduct Monte Carlo simulation or parametric studies with a reservoir simulator. ${ }^{16}$

The simulation model used for this study is the Schlumberger Eclipse 2010 Reservoir Engineering Simulation Software. In "Eclipse Office" a CBM template is available. This template does not utilize a dual porosity model, however it does simulate a single porosity reservoir with gas desorption, like that in coal seams. Because of this feature, the model represents accurate and realistic results.

The Coalbed Methane Template model is very user friendly. It allows the user to quickly create a simulation model with reservoir parameters without knowledge of the simulator input files or keywords. The coalbed methane template consists of the following workflow sections ${ }^{18}$ : 
- Model definition

- Model Title

- Simulation Length and Report Interval

- Reservoir Description

- Layers

- Layer Name

- Depth

- Thickness

- Reservoir Area

○ Rock Properties

- Rock Name

- Fracture Porosity

- Bulk Permeability in X, Y, and Z Direction

- Compressibility

○ Non-Equilibrium Initial Conditions

- Reservoir Pressure

- Water Saturation

- Coal Gas Concentration

- Aquifers

○ Fractures

- Wells

- Hole Diameter

- Well Deviation

○ Lateral Length

- Production

○ Well Controls

- BHP Limit

- Perforation

- Fluid Properties

- PVT Correlation

- Relative Permeability

- Corey Gas Factor

- Corey Water Factor

- Coalbed Methane

- Fluid Property

- CBM Properties Input

- User-defined Langmuir Input

- Simulation Controls

- Economics 


\section{OBJECTIVE AND METHODOLOGY}

The objective of this research project is to develop unique sets of gas and water production type curves on the effects of relative permeability in horizontal wells in coalbed methane reservoirs. The following steps were taken to achieve this objective:

1. Develop a base model to predict gas and water production from a CBM reservoir with a horizontal well.

2. Take the basic CBM reservoir model and determine how relative permeability will impact the gas and water production of the CBM reservoir.

3. Evaluate the effect and importance of other reservoir parameters on the dimensionless production type curves.

4. Develop unique sets of type curves for gas and water production in horizontal wells using a CBM reservoir model.

5. Develop a methodology to use type curves as a reliable tool for predicting the gas and water production behavior in CBM reservoirs.

\subsection{Base Model Development}

The base model created was meant to simulate previous workings of horizontal wells in CBM reservoirs ${ }^{9}$. The model configuration is shown below in Figure 13. It was assumed that this is an under-saturated CBM reservoir with a drainage area of 83.7 acres. This acreage was chosen for ease of entering the length and width into the simulator with a 2:1 ratio. This model follows a horizontal well shape factor because the drainage area shape, $\mathrm{Xe} / \mathrm{Ye}$, the well penetration, $\mathrm{L} / \mathrm{Xe}$, and the dimensionless well length, $\mathrm{L}_{\mathrm{D}}$ are all significant parameters in developing a reliable production analysis. The horizontal permeabilities in the $\mathrm{x}$ and $\mathrm{y}$ directions are different to take into account the anisotropic permeability of the face and butt cleats in coal. In this model, $\mathrm{k}_{\mathrm{x}}$ is 3.3 millidarcies and $\mathrm{k}_{\mathrm{y}}$ is 10 millidarcies. To maximize production, the well is being drilled in the $\mathrm{x}$ direction, perpendicular to the direction with the highest permeability. All parameters used were selected from previous publications and are shown in Table 3. 
Table 2. Input Parameters for Base Model

\begin{tabular}{|c|c|c|c|}
\hline \multicolumn{2}{|c|}{ Input Parameters } & Horizontal Model & Value \\
\hline \multicolumn{2}{|c|}{ Porosity Model } & \multicolumn{2}{|c|}{ Single Porosity with Desorption } \\
\hline \multicolumn{2}{|c|}{ Model Shape and Geometry } & \multicolumn{2}{|c|}{ Rectangle, One Layer -2D } \\
\hline \multicolumn{2}{|c|}{ Period of Production } & - & 25 years \\
\hline \multicolumn{2}{|c|}{ Grid Size } & - & $100 \mathrm{ft} \times 100 \mathrm{ft}$ \\
\hline \multicolumn{2}{|c|}{ Reservoir Area } & - & 83.7 acres \\
\hline \multicolumn{2}{|c|}{ Hole Diameter } & - & 4 in \\
\hline \multicolumn{2}{|c|}{ Lateral Length } & - & $1350 \mathrm{ft}$ \\
\hline \multirow{13}{*}{$\begin{array}{l}\text { Reservoir } \\
\text { Parameters }\end{array}$} & \multirow{4}{*}{ Layers } & Depth & $1200 \mathrm{ft}$ \\
\hline & & Thickness & $12 \mathrm{ft}$ \\
\hline & & Length (Ye) & $2700 \mathrm{ft}$ \\
\hline & & Width (Xe) & $1350 \mathrm{ft}$ \\
\hline & \multirow{6}{*}{ Rock Properties } & Fracture Porosity & $0.017 \mathrm{mD}$ \\
\hline & & Bulk X-direction Permeability & $3.3 \mathrm{mD}$ \\
\hline & & Bulk Y-direction Permeability & $10 \mathrm{mD}$ \\
\hline & & Bulk Z-direction Permeability & $1 \mathrm{mD}$ \\
\hline & & Coal Compressibility & $1.00 \mathrm{E}-06$ \\
\hline & & Rock Density & $89.63 \mathrm{lb} / \mathrm{ft}^{3}$ \\
\hline & \multirow{3}{*}{$\begin{array}{c}\text { Initial } \\
\text { Conditions }\end{array}$} & Reservoir Pressure & $650 \mathrm{psia}$ \\
\hline & & Water Saturation & $100 \%$ \\
\hline & & Coal Gas Concentration & $0.00728 \mathrm{Mscf} / \mathrm{ft}^{3}$ \\
\hline \multirow{18}{*}{ Fluid Properties } & \multirow{4}{*}{$\begin{array}{c}\text { PVT } \\
\text { Correlations }\end{array}$} & Reference Temperature & $90 \mathrm{~F}$ \\
\hline & & Gas Gravity & 0.7 \\
\hline & & Reference Pressure & $650 \mathrm{psia}$ \\
\hline & & Maximum Pressure & $780 \mathrm{psia}$ \\
\hline & \multirow{3}{*}{$\begin{array}{c}\text { Relative } \\
\text { Permeability } \\
\text { Gas }\end{array}$} & Corey Gas Factor & 2 \\
\hline & & Sgrw & 0 \\
\hline & & $\operatorname{Krg}($ Swmin $)$ & 1 \\
\hline & \multirow{5}{*}{$\begin{array}{c}\text { Relative } \\
\text { Permeability } \\
\text { Water }\end{array}$} & Corey Water Factor & 3 \\
\hline & & Swmin & 0.3 \\
\hline & & SwCrit & 0.3 \\
\hline & & Krw (Sgrw) & 1 \\
\hline & & $\mathrm{Kr}(100 \%$ Sat $)$ & 1 \\
\hline & \multirow{6}{*}{$\begin{array}{l}\text { Coalbed } \\
\text { Methane }\end{array}$} & Gas Diffusion Coefficient & $1 \mathrm{ft}^{2} /$ day \\
\hline & & Gas Desorption Time & 30 days \\
\hline & & Critical Desorption Pressure & $350 \mathrm{psia}$ \\
\hline & & Coal Re-absorption Factor & 1 fraction \\
\hline & & Langmuir Pressure & $675.6 \mathrm{psia}$ \\
\hline & & Langmuir Concentration & $0.0213 \mathrm{Mscf} / \mathrm{ft}^{3}$ \\
\hline \multicolumn{2}{|c|}{ Production Limits } & Bottom Hole Pressure & 80 psia \\
\hline
\end{tabular}




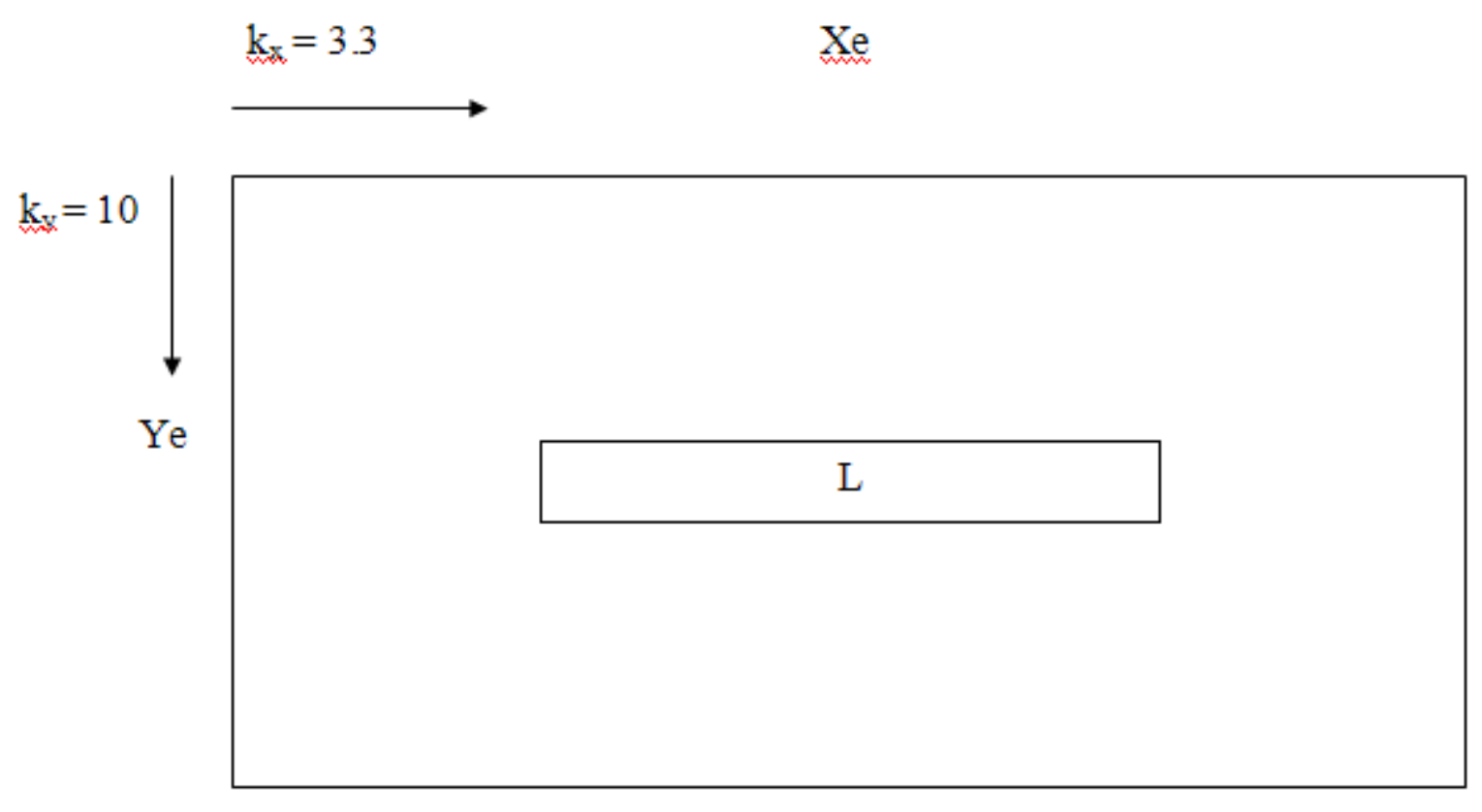

Figure 13. Base Model Configuration

\subsection{Impact of Relative Permeability}

The impact of different reservoir parameters on the production behavior of a horizontal well was investigated in order to establish a unique set or type curves. The reservoir parameter of most interest in this study is the relative permeability, particularly the gas and water relative permeability exponents, n' and m', respectively. The exponents were varied over a range of values given from previous work in vertical wells. The values were changed one at a time to compare different drainage areas during the investigation. The relative permeability characteristics have proven in past research to have significant impact on gas and water production in CBM reservoirs due to the two-phase flow conditions. Other reservoir parameters were kept constant, such as the critical desorption pressure at 350 psia. Also, the permeability values in both $\mathrm{x}$ and $\mathrm{y}$ directions were constant at $3.3 \mathrm{md}$ and $10 \mathrm{md}$, respectively. A list of all the input parameters used for the base case model is shown in Table 2. The ranges of parameters used in the simulations are shown below in Table 3. 
Table 3. Range of Parameters

\begin{tabular}{|c|c|c|}
\hline PARAMETERS & Range & Values used \\
\hline Reservoir Shape & Rectangle & Rectangle \\
\hline Area (acres) & $41-83.6$ (Rectangle) & 41,83 \\
\hline Lateral length Ratio (L/Xe) & $0.5-0.75$ & $0.5,0.75$ \\
\hline Rectangle Lateral Length (ft) & $475-2025$ & $\begin{array}{c}40 \text { acre }-(475,950,1425) \\
80 \text { acre }-(675,1350,2025)\end{array}$ \\
\hline Corey Gas Factor & $2-6$ & $\mathrm{n}^{\prime}-(2,3,4,5,6)$ \\
\hline Corey Water Factor & $1-3$ & $\mathrm{~m}^{\prime}-(1,2,3)$ \\
\hline
\end{tabular}

\subsection{Other Model Parameters}

The other parameters used in this study to create a realistic reservoir were chosen from previous workings. The original work in this area was performed by Dylan Drinkard in 2009. The base model in this study was derived from using Drinkard's original input parameters. Similar to Drinkard's work, this study also investigates the effects of reservoir parameters in different reservoir areas of 40 and 80 acres. Also, different lateral lengths were used to in each reservoir area to compare the effects of well length.

\subsection{Dimensionless Groups for Type Curve Development}

One very unique characteristic of a horizontal CBM well is the different flow regimes as previously discussed. Because of this, one unique type curve will not be sufficient or accurate as would be in vertical or conventional wells. The assumption is made that two different dimensionless groups will be needed to separate linear flow from radial flow for the gas rate type curves. This assumption was determined in previous research studies. ${ }^{9}$ The first dimensionless group will be needed to represent the linear flow regime. This group will illustrate the early stage of the well up until the peak gas production rate. The second dimensionless group will be used to predict the production behavior for the remaining life of the well. Only one type curve will be needed to represent the water production rate type curves for the entirety of the well.

In order to establish the unique type curves, the dimensionless groups were developed using equations 2.6 through 2.11. The first dimensionless group represents the linear flow 
regime. As mentioned before, linear flow is present in the well up until the peak production rate is reached. For the early life of the gas production type curve, $\mathrm{L}_{\mathrm{D}}$, calculated by Equation 2.15, was multiplied by $\mathrm{t}_{\mathrm{gD}}$, found in Equation 2.6.

The second dimensionless group represents the elliptical/radial gas flow regime. This flow regime is present starting after the peak production rate throughout the remaining life of the well. The dimensionless group used to represent this flow regime is $\mathrm{t}_{\mathrm{gD}}$ shown in Equation 2.6. As previously mentioned, the water production type curves are represented by only one dimensionless group throughout the entire life of the well. The dimensionless groups used for the water production type curves are represented in equations 2.9 and 2.10.

\subsection{Methodology for Type Curve Application}

In order to predict gas and water production behavior, it is necessary to estimate $\mathrm{q}_{\text {peakD }}$ as explained earlier. The equation defines the dimensionless peak gas rate for horizontal wells as:

$$
q_{\text {peak }}{ }_{g D}=q_{\text {peak }} * \frac{1422 T \mu_{c} z_{c}}{k h\left(P_{c}^{2}-P_{w f}{ }^{2}\right)} \quad \ln \frac{r_{e}}{r_{w}}-0.738+s+s_{C A}-c^{\prime} \ldots
$$

A linear regression analysis was performed to develop the correlation of the impact of different reservoir parameters on the dimensionless peak production rate. The reservoir parameters used in developing the correlation were m', n', and L/Xe ratio. The most significant of the chosen parameters to correlate are m' and n' because they have reasonable impact on the gas production in CBM reservoirs. From the correlation generated from the regression, the calculated $\mathrm{q}_{\text {peakD }}$ was compared with the $\mathrm{q}_{\text {peakD }}$ given from the simulation.

\subsection{Case Study for Verification}

In order to evaluate the accuracy and reliability of the gas and water production type curves and the correlation for $\mathrm{q}_{\mathrm{peakD}}$, a verification case study was performed. A set of reservoir parameters that had not been previously used in this study were chosen as inputs to compare the reservoir simulator results with the predictions from the type curves using the peak gas rate. The case study inputs are summarized in Table 4. 
Table 4. Input Parameters for Case Study

\begin{tabular}{|c|c|}
\hline Parameters & Values \\
\hline Area & 80 Acres \\
\hline L/Xe Ratio & 0.65 \\
\hline Corey Gas Factor (n') & 3.25 \\
\hline Corey Water Factor (m') & 1.75 \\
\hline Fracture Permeability (x,y) (md) & $3.3,10$ \\
\hline Fracture Porosity (\%) & 1.7 \\
\hline Thickness (ft) & 12 \\
\hline Reservoir Pressure (pisa) & 650 \\
\hline Langmuir Pressure (psia) & 675.6 \\
\hline Langmuir Volume (Mscf/ft $\left.{ }^{3}\right)$ & 0.0213 \\
\hline L (ft) & 1755 \\
\hline Xe (ft) & 2700 \\
\hline Ye (ft) & 1350 \\
\hline
\end{tabular}




\section{RESULTS AND DISCUSSION}

Many type curves were developed during this study in order to assist in the prediction of production behavior of horizontal wells in CBM reservoirs. These type curves can serve as a quick and reliable tool for production performance, prediction, and production data analysis of gas and water throughout the life of the well. Relative permeability data in CBM reservoirs is very limited and difficult to obtain. The type curves developed in this study provide accurate data that can aid in the prediction of gas and water production in horizontal wells. This area of research has previously been studied in vertical wells but never before in horizontal wells. Fortunately the modeling software used for this project has proven to be reasonably accurate and reliable. The effects of relative permeability in horizontal wells are illustrated in the following figures for all rectangular drainage areas.

When the peak gas production rate has been reached, the well enters the third flow phase. By this time during the life of the well, most of the water in a CBM reservoir should have been produced. Any water that is still producing in the third flow phase can be considered negligible. Because of this, relative permeability in late time production of a CBM reservoir is irrelevant. Therefore, the results in this section focus primarily on the early time production, when the relative permeability has the most impact on the type curves.

The first set of simulations evaluate the impact of varying the gas relative permeability exponent, n', when the water relative permeability exponent, m', remains constant at a value of three. Figure 14 shows the early production type curve for the 80 acre model with well length of 1350 feet.

The water production type curves were also investigated to determine what impact the relative permeability had. Figure 15 shows the water production type curve for the 80 acre model when $\mathrm{m}^{\prime}=3$. The gas relative permeability exponent had little effect on the water production type curve.

Similar simulations were run using the same reservoir model parameters except for m'. As the water relative permeability was decreased to two and then again to one, the same results 
were observed as before. The gas relative permeability exponent had effect on the gas type curve however had very little effect on the water type curve.

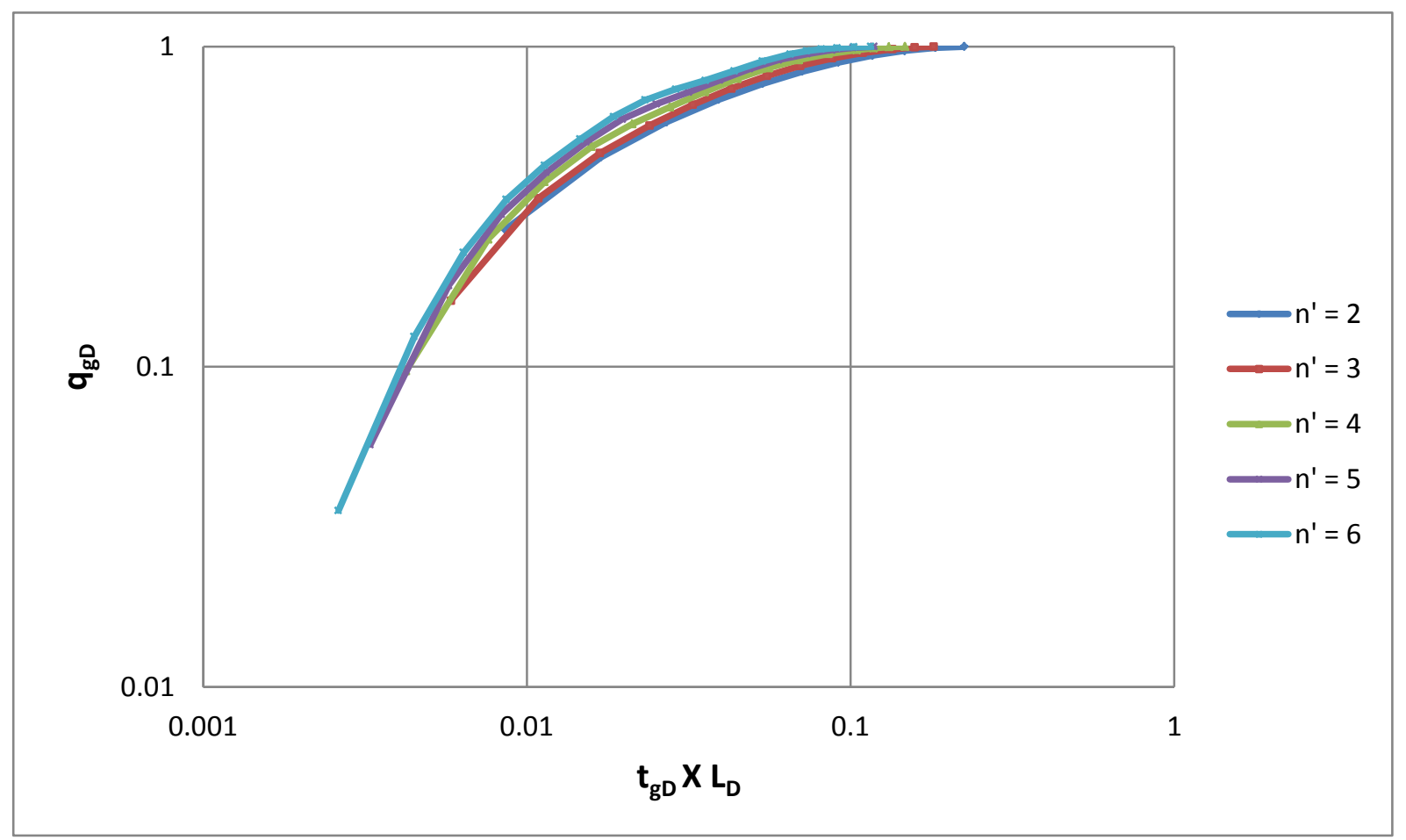

Figure 14. 80 Acre Early Time Gas Production for m’ = 3

Another analysis on this data was to view the results as m' was varied from one to three as n' remained constant. These results can be seen in the Figures 16, 17 and 18 .

Figure 16 shows that the production rate decreases as m' increases in the early time type curve when n' remains constant at a value of two. This same result was observed as more type curves were developed as n' was increased from two to six. Figure 17 illustrates that after the peak production rate, $\mathrm{m}$ ' has very little effect on the gas production rate. This too was observed in all cases of varying n'. Figure 18 shows the water production type curve as m' is varied from one to three when n' remains constant at two. According to the plot, the water relative permeability exponent has very little effect on the water type curve when n' is small. As n' was made large, m' began to have more effects on the type curve. This can be seen in Figure 19 below. 


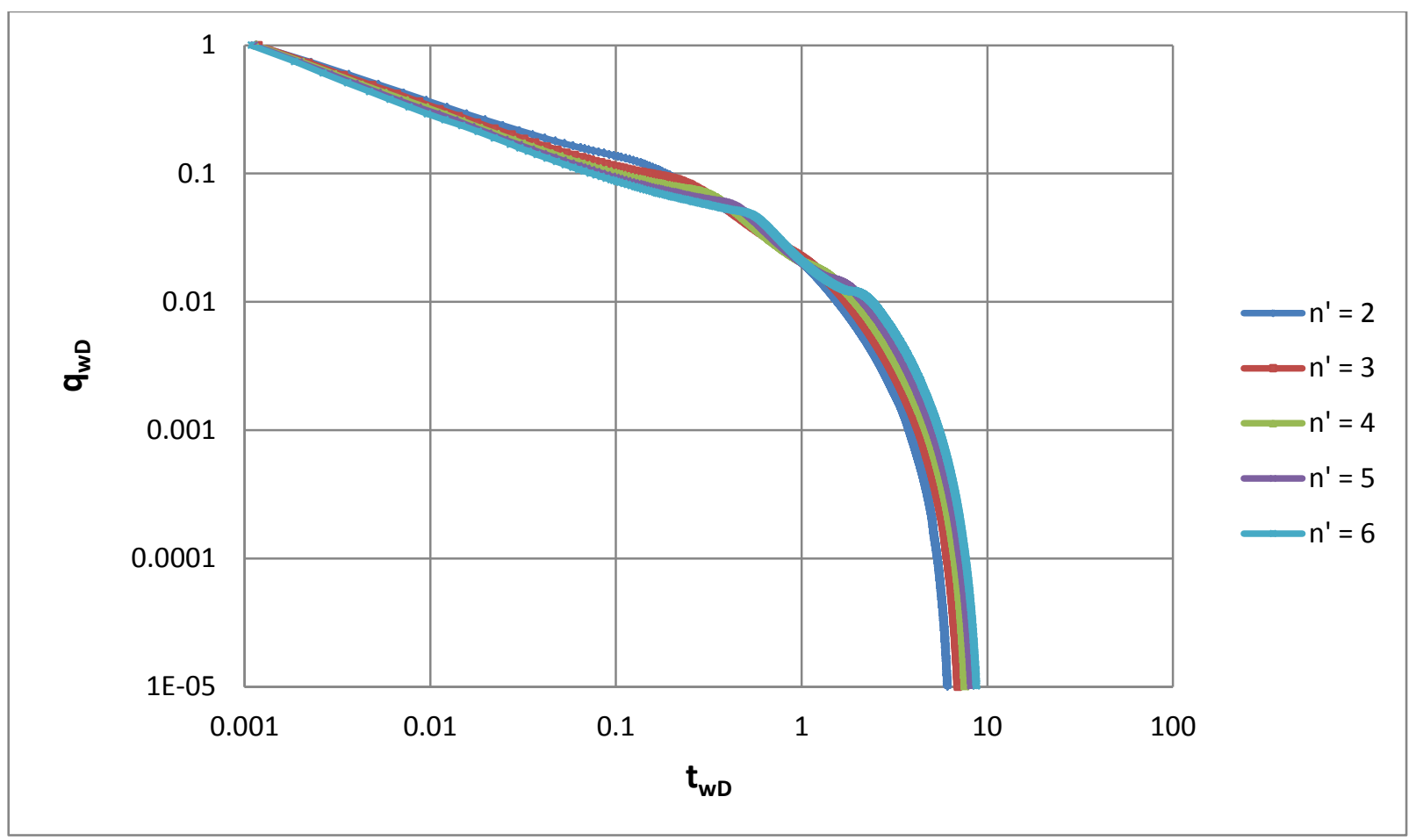

Figure 15. 80 Acre Water Production for m' $=3$

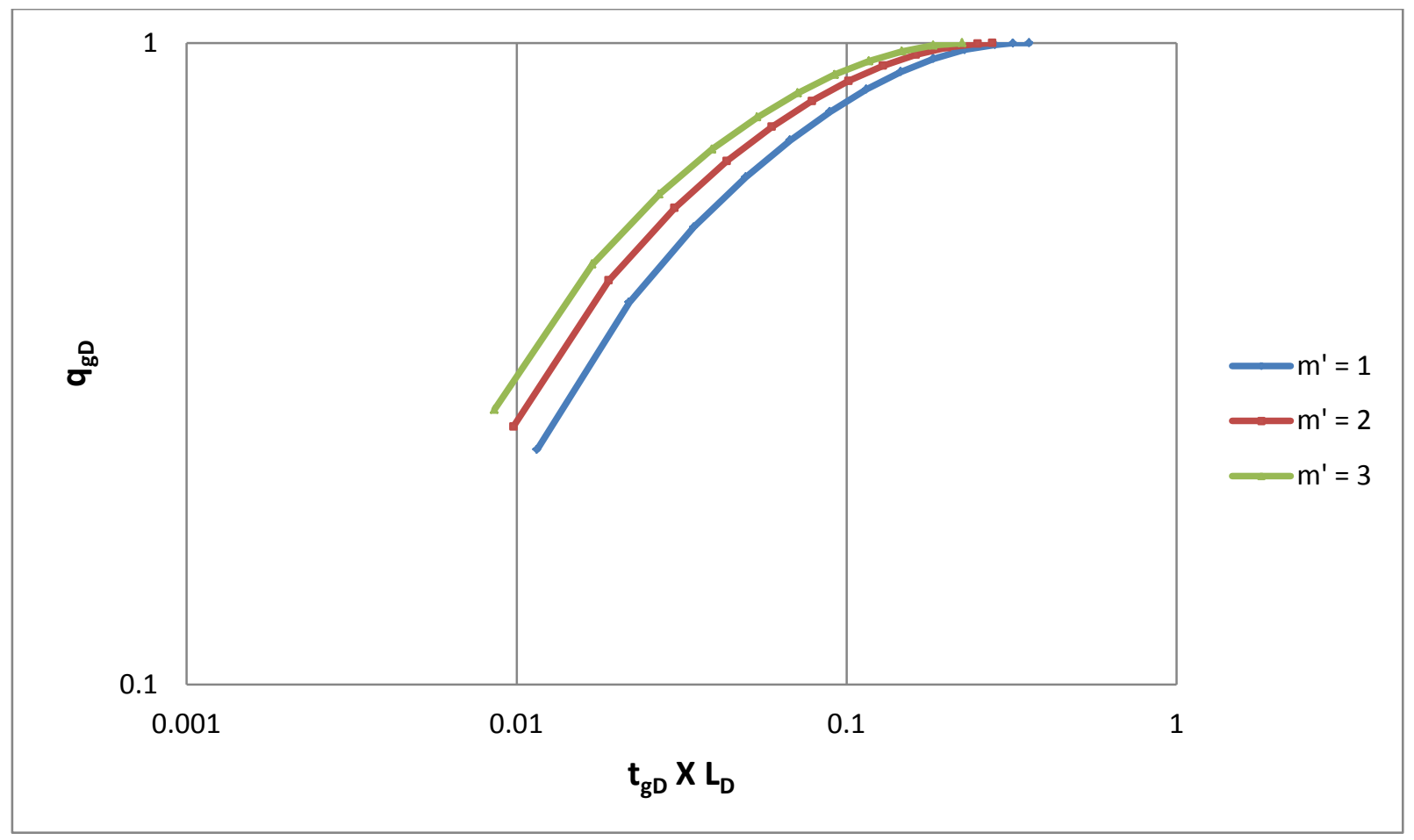

Figure 16. 80 Acre Early Time Gas Production for n' = 2 


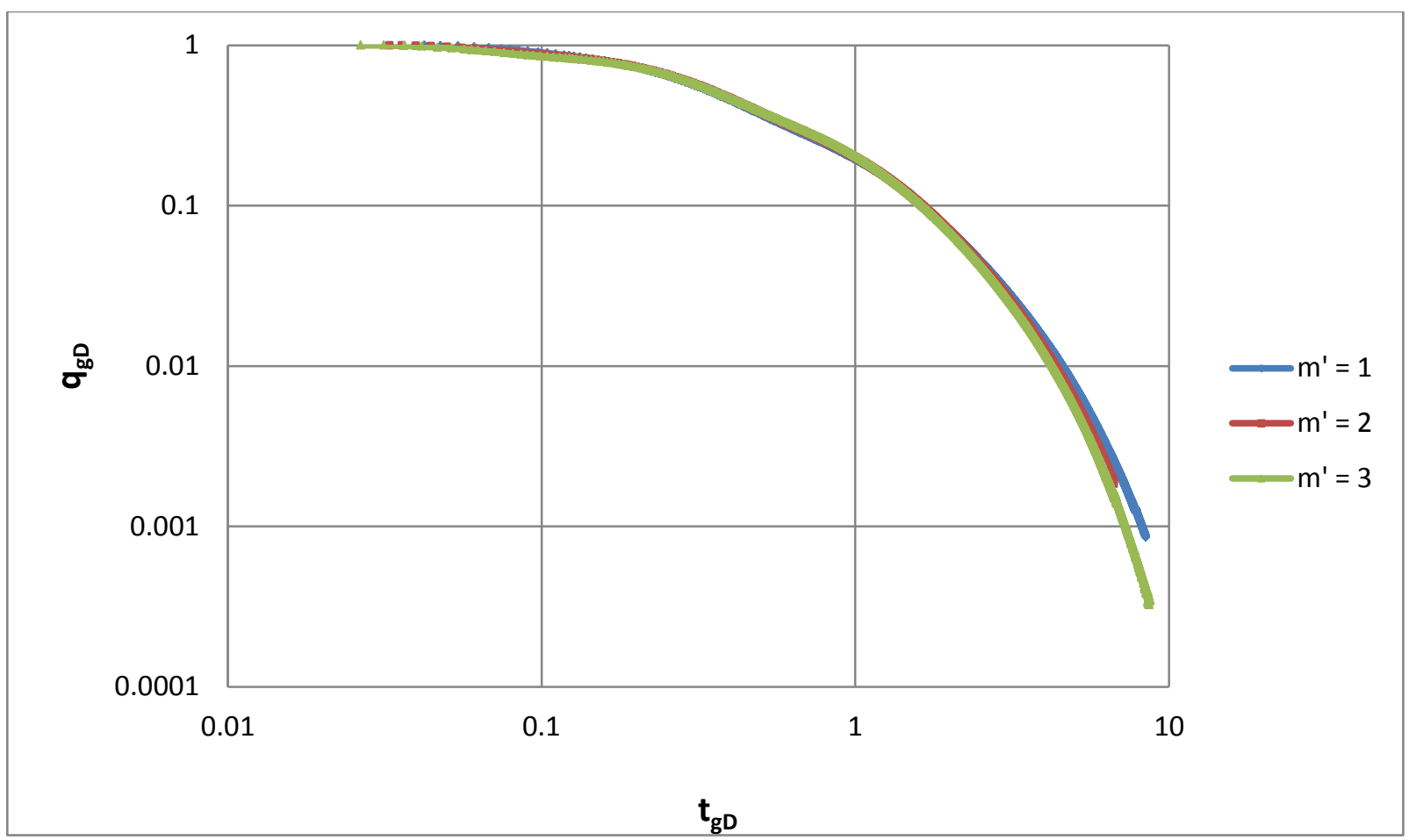

Figure 17. 80 Acre Late Time Gas Production for n' $=2$

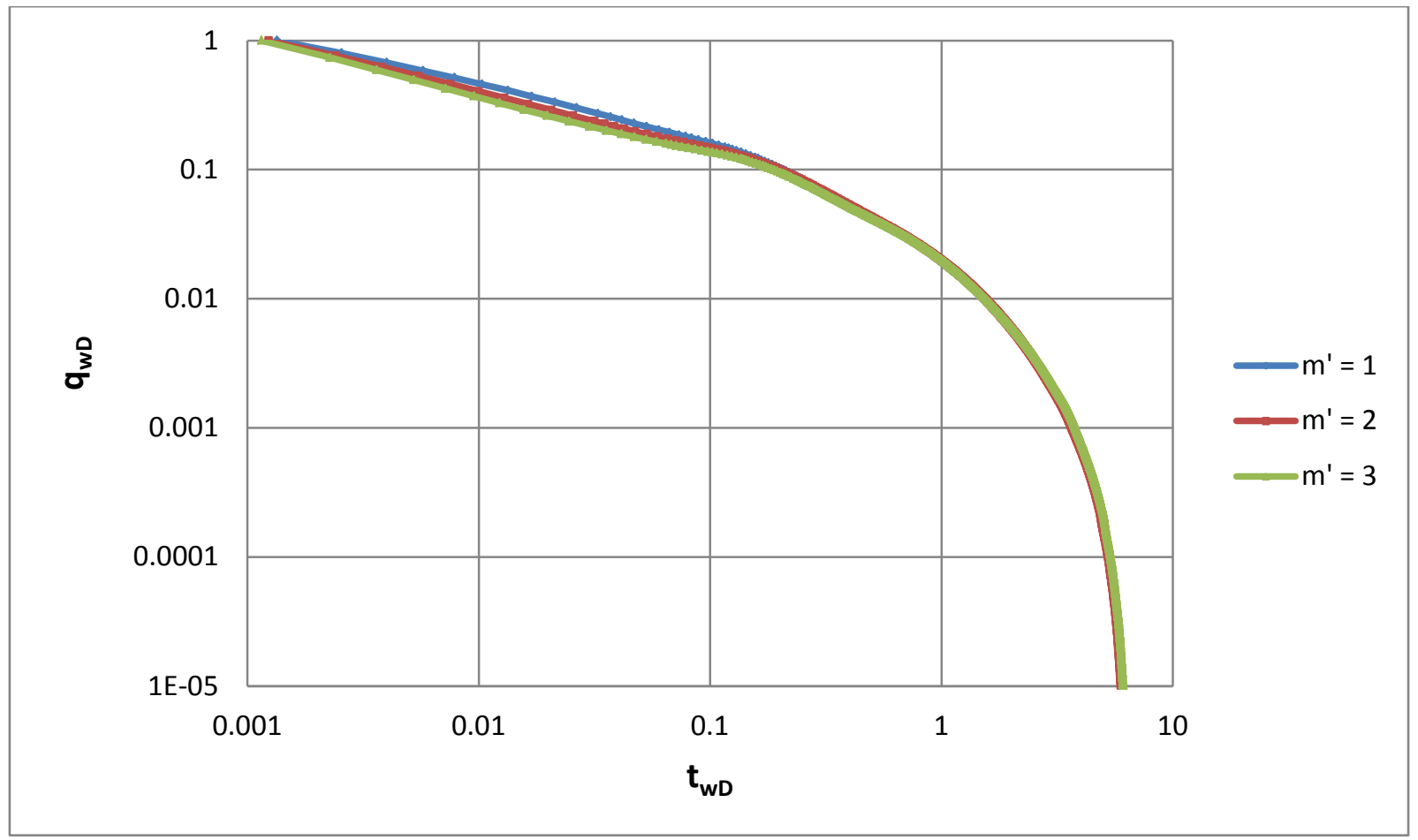

Figure 18. 80 Acre Water Production for n’ $=2$ 


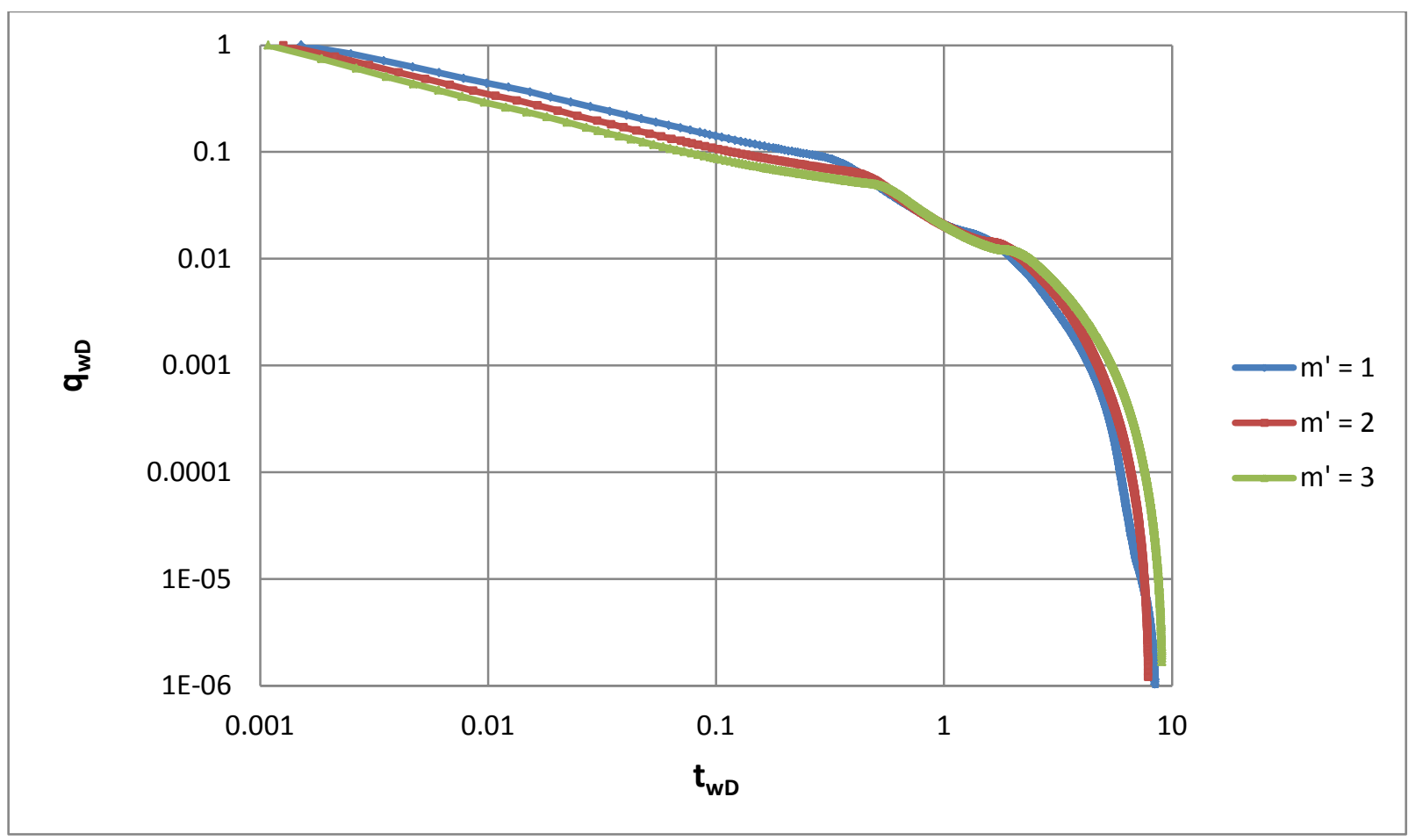

Figure 19. 80 Acre Water Production for n’ $=6$

The next set of simulations ran was to investigate the same effects of relative permeability only on a smaller reservoir area. In order to make an even comparison between reservoirs with different areas, the well ratio between the well lateral length, L, and the reservoir length, Xe, was kept at 1:2. The impact of relative permeability on the 40 acre reservoir proved to be very similar to that of the 80 acre reservoir. The results can be seen in the following figures.

Figure 20 illustrates the early time gas production type curve for the 40 acre reservoir. The water production type curve in Figure 21 also follows the same pattern as the 80 acre reservoir when m' equals three. Early in the production of the well, n' seems to have little to no effects on the water production. Later in the life of the well, as n' increases, the water production decreases less gradual. 


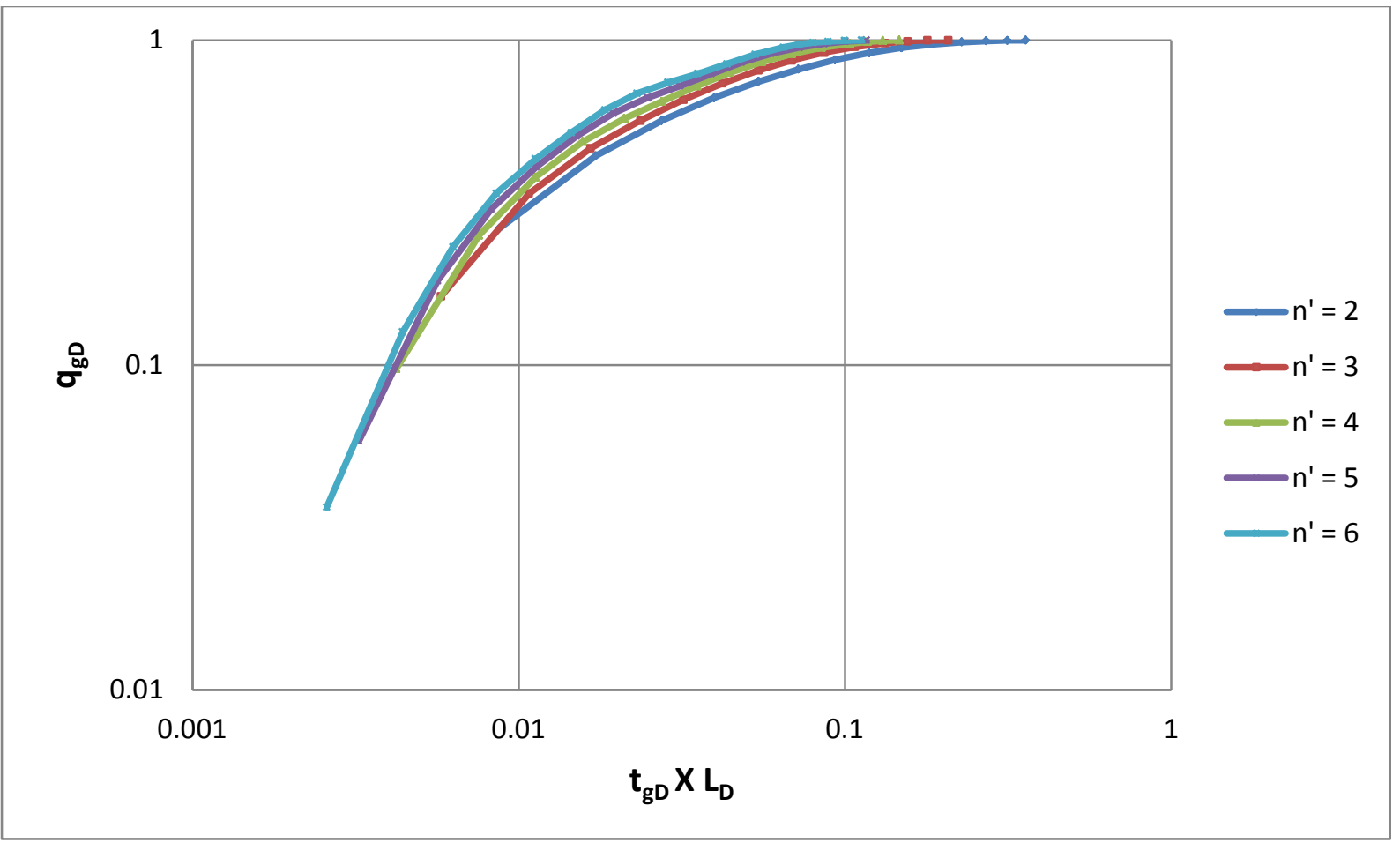

Figure 20. 40 Acre Early Time Gas Production for m’ = 3

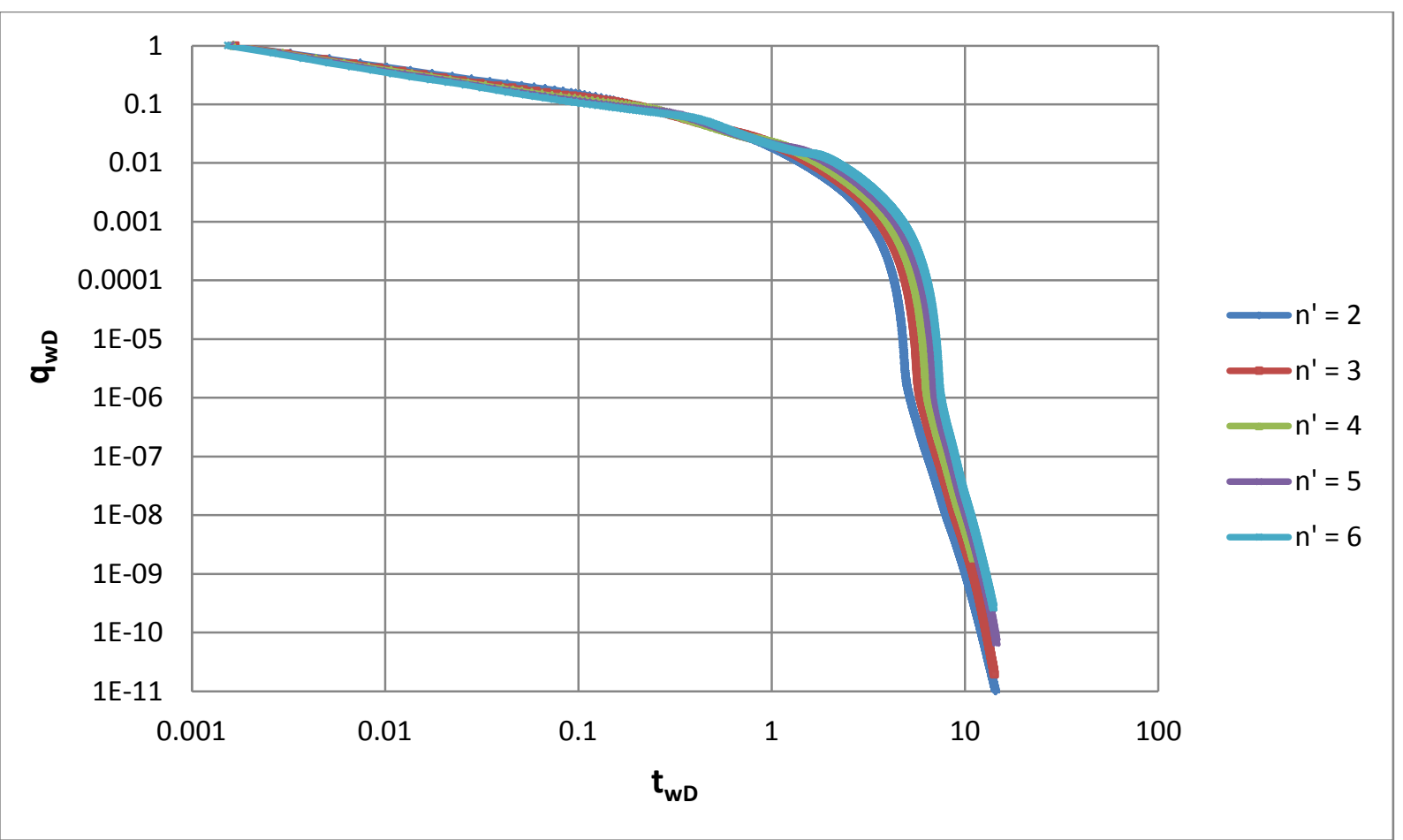

Figure 21. 40 Acre Water Production for m’ = 3 
The next investigation, as before, compares the effects of the water relative permeability exponent, m', as the gas relative permeability exponent, n', remains constant for the 40 acre reservoir. Figures 22 through 24 show the results of m' when n' equals two.

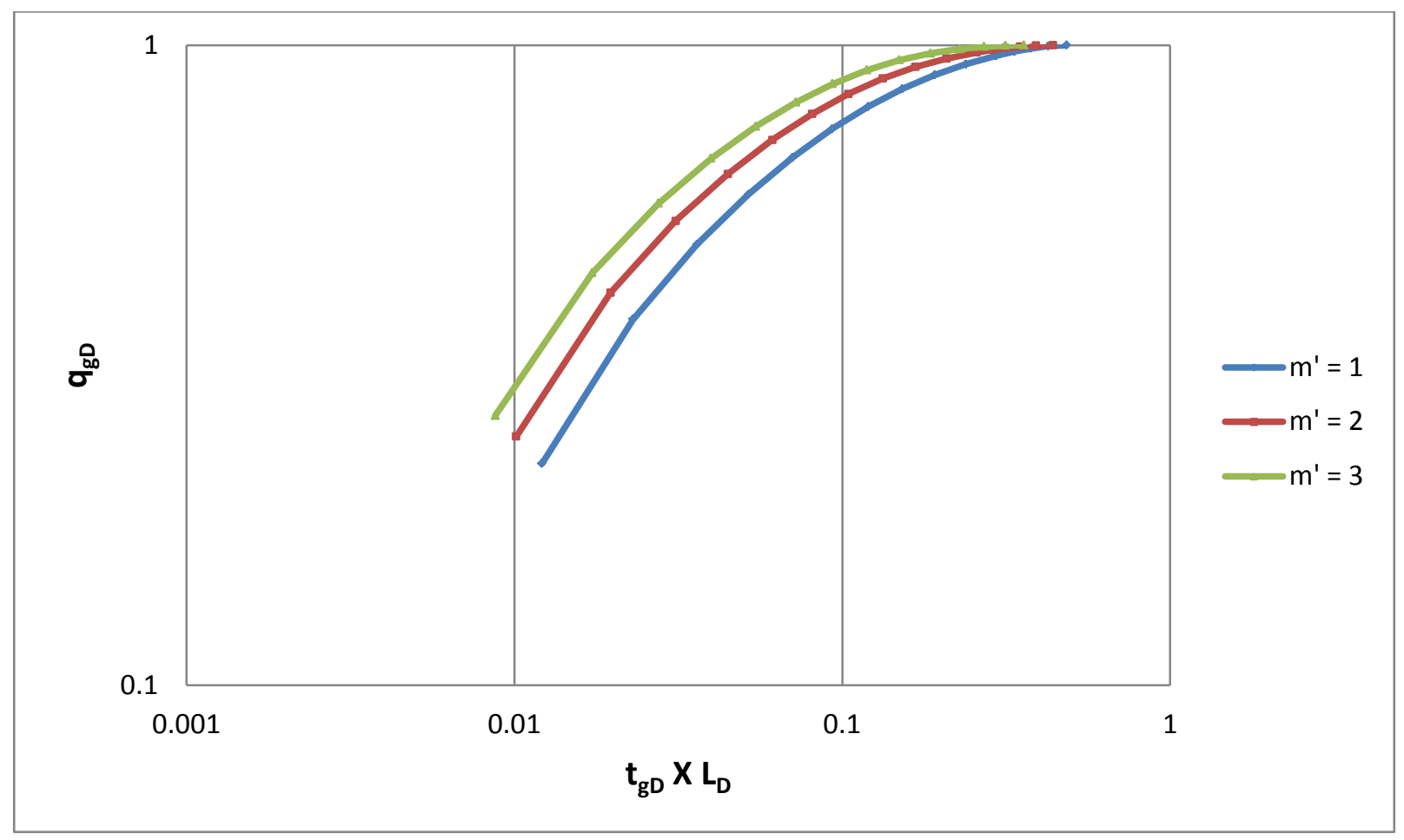

Figure 22. 40 Acre Early Time Gas Production for n’ $=2$

As shown in Figure 22, the value of m' seems to have a small effect on the early time gas production type curve. As m' increases, the gas flow rate decreases until the peak production rate is reached. After the peak production flow rate has been reached, m' seems to have very little effect on the flow rate for the remaining life of the well when n' equals two as shown in Figure 23. This same pattern was maintained throughout all the simulations as n' was increased from two to six in the 40 acre reservoir. These results were expected after running the same analysis on the 80 acre reservoir. Figure 24 shows the water production type curve when n' equals two. When n' is small, m' does not drastically affect the water production rate. However, similar to the 80 acre reservoir, as n' becomes large, there is a more dramatic affect on the type curve as m' is varied from one to three. This is shown in Figure 25. 


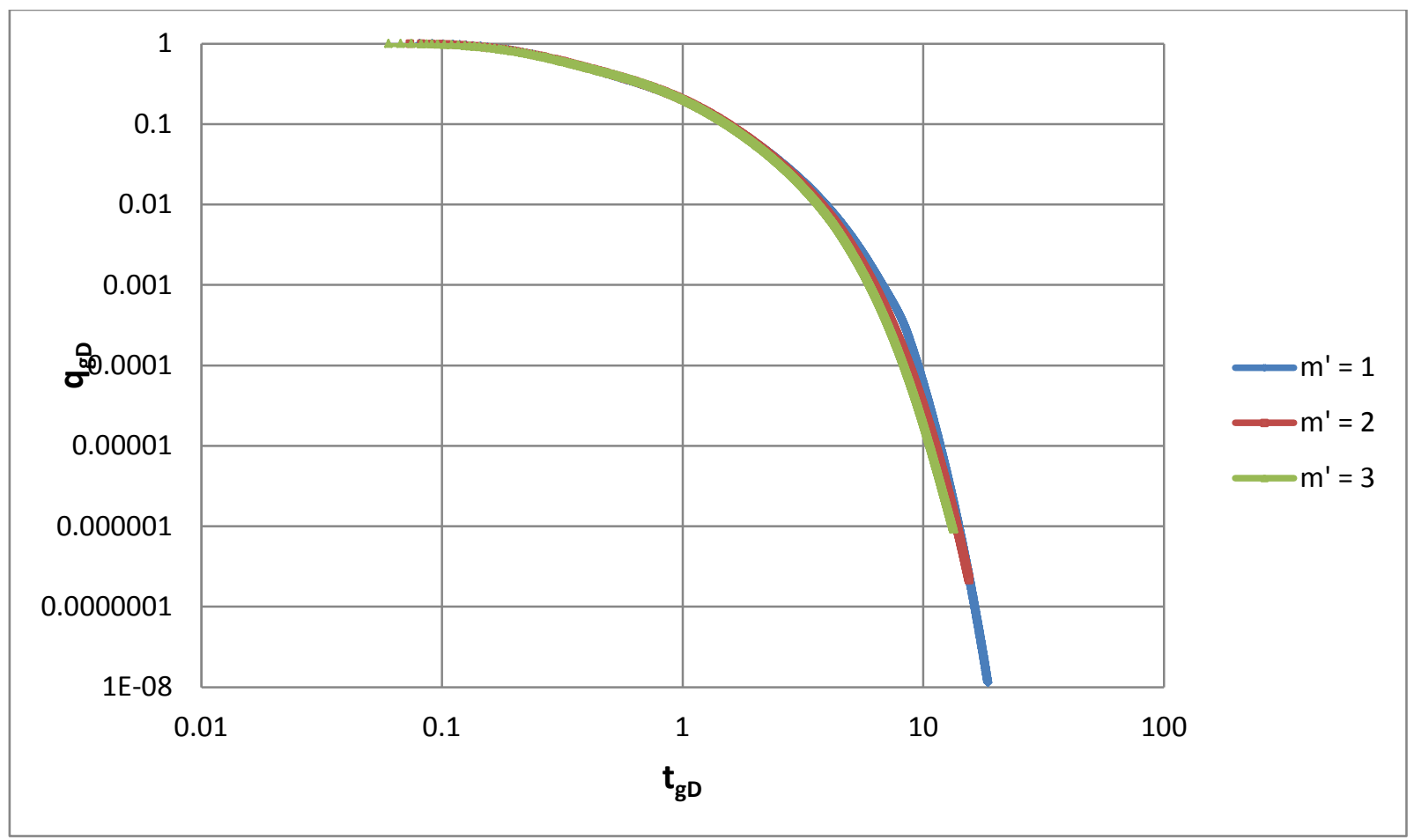

Figure 23. 40 Acre Late Time Gas Production for n' $=2$

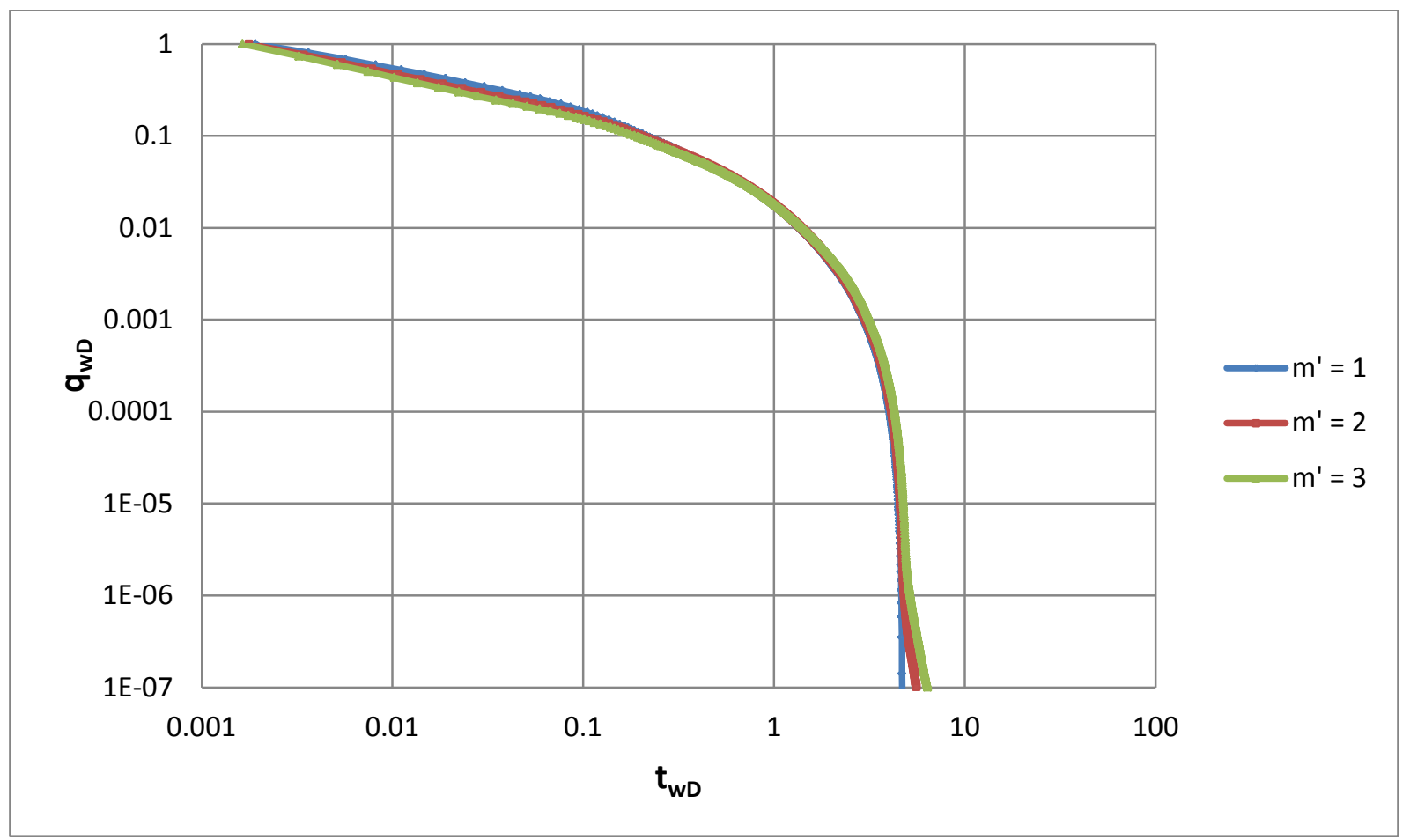

Figure 24. 40 Acre Water Production for n’ $=2$ 


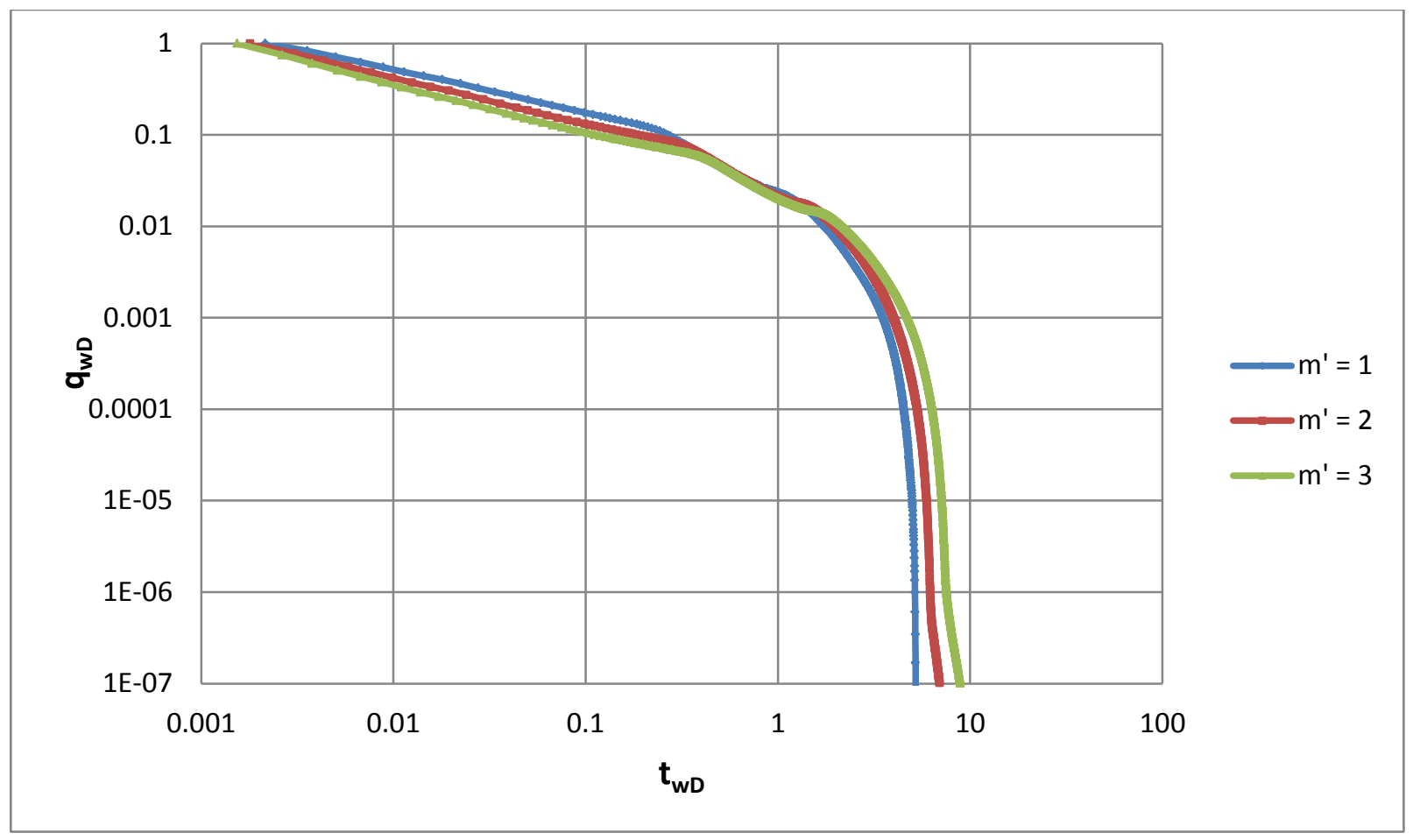

Figure 25. 40 Acre Water Production for n' $=6$

Another comparison that was made during this study was between different lateral lengths, more specifically between the L/Xe Ratio. Two cases were investigated, $\mathrm{L} / \mathrm{Xe}=0.5$ and $\mathrm{L} / \mathrm{Xe}=0.75$ for both reservoir areas. The results are plotted in Figures 26 through 28 . It can be seen from these figures that the production depends on the lateral well length. In Figures 26 and 27 , the curves for both reservoir areas follow the same curvature when $m^{\prime}=3$ and n' is varied from two to six. In Figure 30, each case is more widely spaced. This means as m' increases the production rate decreases and begins later. This is because with higher m' values, the water relative permeability decreases, making it harder to produce the water. Therefore, with low values of m', the water is more easily produced making it easier to drop the pressure and allow the gas to diffuse from the coal matrix. As water is more rapidly produced, more gas is desorbed from the coal matrix. Also shown in Figure 28, dropping the value of m' has the same effect as increasing the well length. 


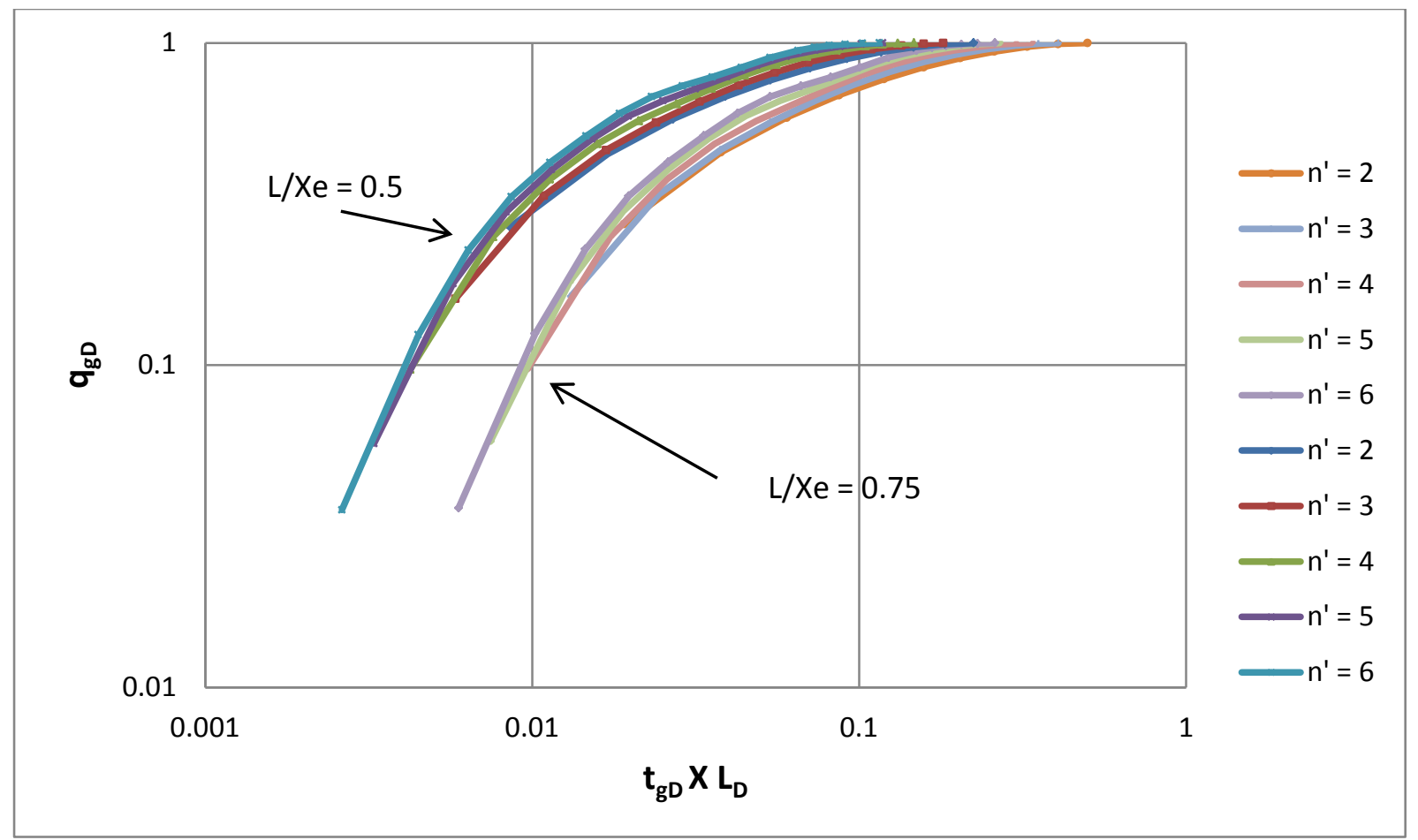

Figure 26. 80 Acre L/Xe Comparison Early Gas Curve for m’ = 3

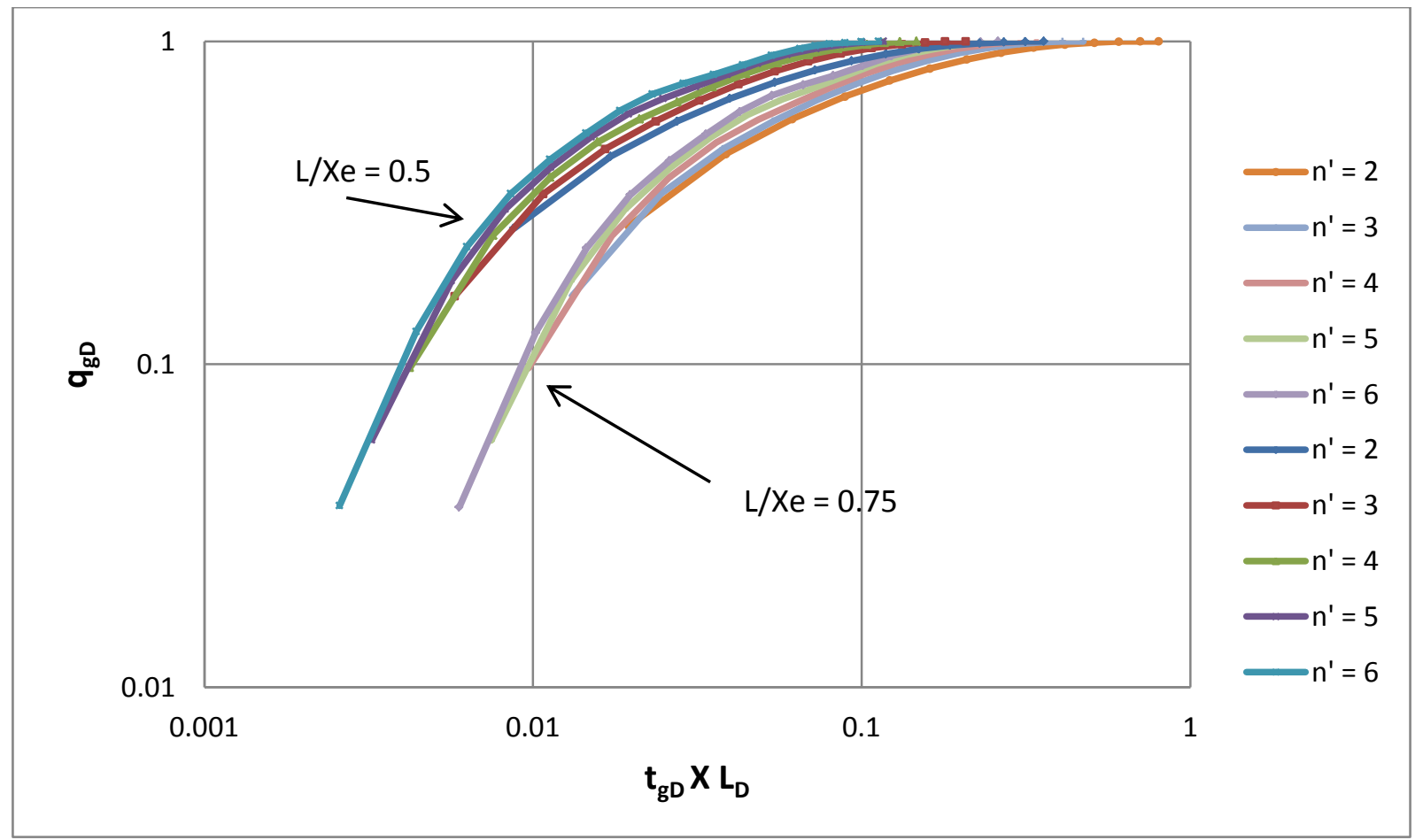

Figure 27. 40 Acre L/Xe Comparison Early Gas Curve for m’ = 3 


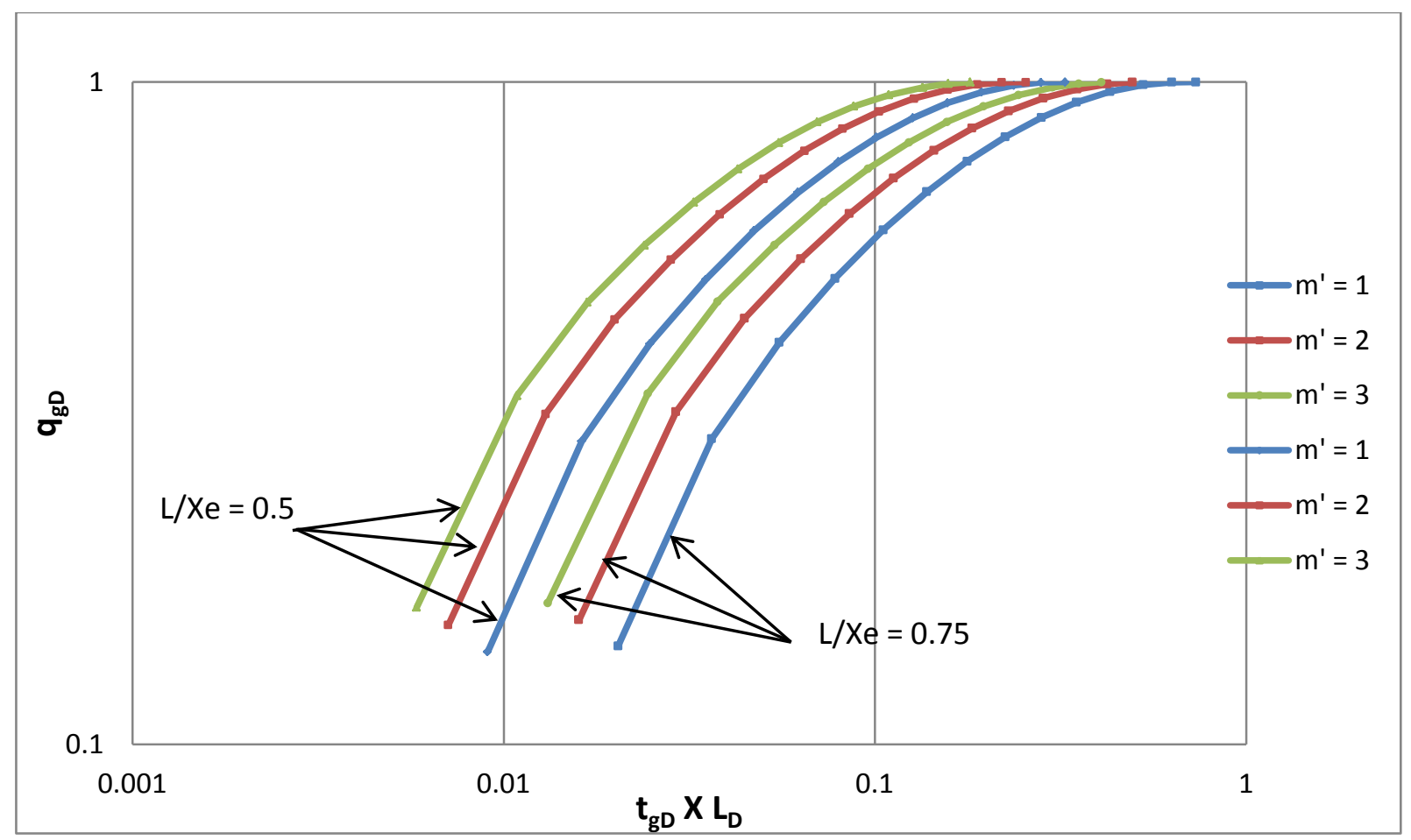

Figure 28. 80 Acre L/Xe Comparison Early Gas Curve for n' $=3$

After collecting all the data from each simulation, a linear multiple regression was completed as previously explained. Once the parameters were analyzed, a multiple linear regression developed the following correlation $\left(R^{2}=0.882066\right)$ :

$$
Q_{\text {peakD }}=0.036046 n^{\prime}+0.041025 m^{\prime}-0.38164 \frac{L}{X_{e}}-0.16356
$$

Equation 4.1 can be used to calculate the dimensionless peak gas rate for any case of interest. A test case study was performed to evaluate the margin of error for the calculated equation. The equation generated from the linear multiple regression proved to be accurate and reliable. The estimated $\mathrm{q}_{\text {peakD }}$ from Equation 4.1 was -0.22268. Using this value in Equation 3.1, $\mathrm{q}_{\text {peak }}$ was found to be $359.33 \mathrm{Mscf} / \mathrm{D}$. The same test case was tested in the simulator, giving a value of $343.88 \mathrm{Mscf} / \mathrm{D}$. This yields a $4.49 \%$ error in the generated correlation. This concludes that the correlation developed for $\mathrm{q}_{\mathrm{peakD}}$ can provide reliable results. 


\section{CONCLUSIONS AND RECOMMENDATIONS}

The importance of this research was to investigate the impact of relative permeability of horizontal wells in coalbed methane reservoirs. From the data gathered, a unique set of type curves were to be developed for the use of independent producers to evaluate and predict gas and water production behavior for horizontal wells. Based on the results, the following conclusions and recommendations were made:

1. The effect of relative permeability was studied to evaluate the impact on type curves. The gas and water relative permeability exponents had significant effects on both gas and water type curves.

2. Two dimensionless groups are needed for developing type curves for horizontal CBM wells to distinguish between early and late time flow.

3. The water relative permeability exponent, m', had a significant effect on the early time gas production type curve until the peak gas rate was reached. The gas relative permeability exponent, n', also had a significant effect on the gas production type curve until the peak production rate was reached.

4. Neither n' nor m' seemed to have major effects on the water production type curves.

5. Different reservoir areas produced very similar results.

6. A reliable correlation for predicting the peak gas rate for CBM horizontal wells was developed that allowed the type curves to be used as a tool for predicting production.

Even though the different reservoir areas produced nearly the same results, the smaller reservoir area formed a smoother curve throughout the simulations. The larger reservoir area results appear to be accurate and reliable; however more research and simulations using the same model should be performed to eliminate the variance in the curves. This research can be helpful in the development and implications of new technology and growth for CBM reservoirs. The results lead to a quick and reliable tool for estimating the gas and water production for independent gas producers. 


\section{NOMENCLATURE}

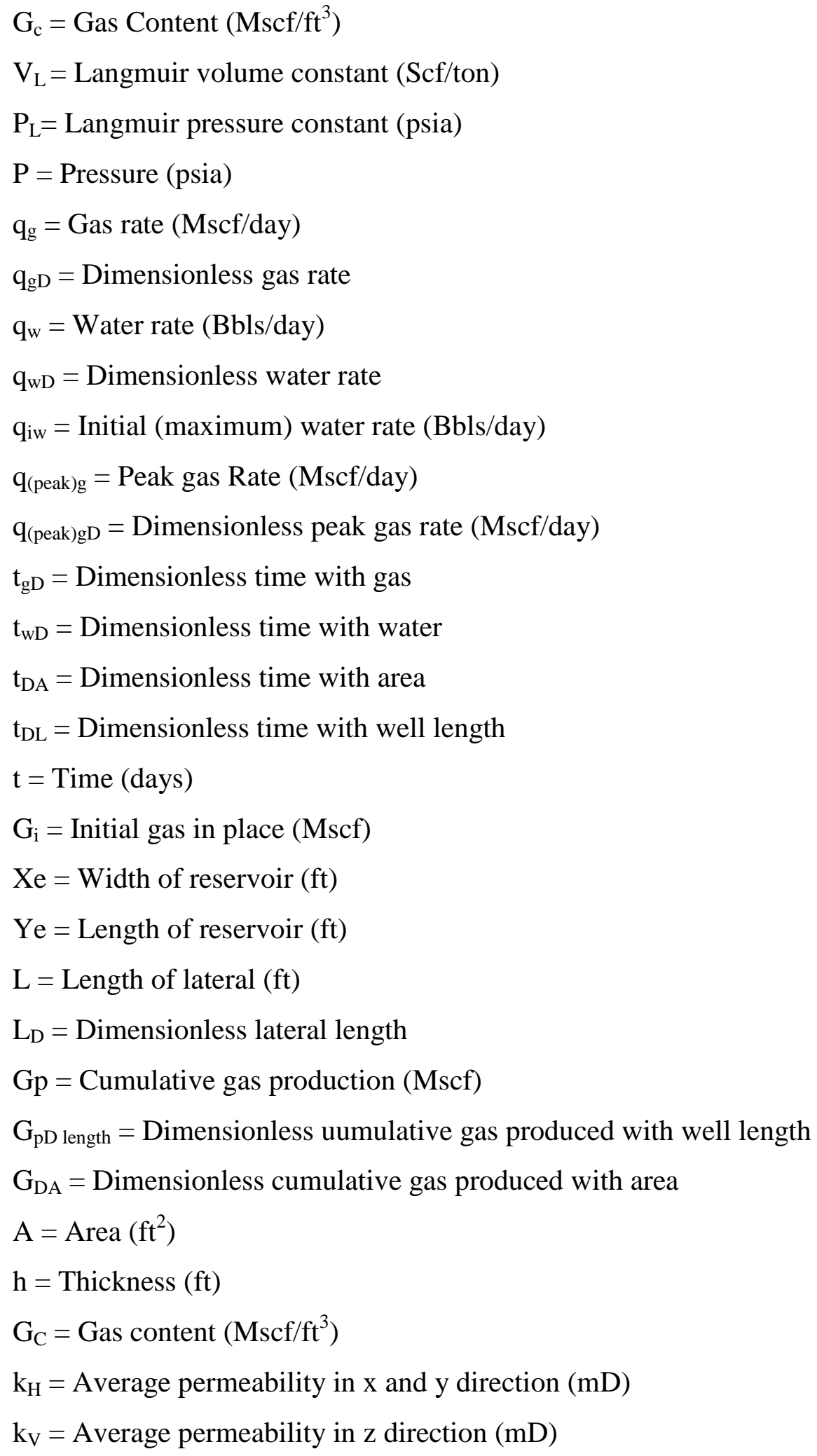


$\mathrm{k}_{\mathrm{ri}}=$ Relative permeability

$\mathrm{k}_{\mathrm{i}}=$ Effective permeability $(\mathrm{mD})$

$\mathrm{k}_{\mathrm{b}}=$ Base permeability $(\mathrm{mD})$

$\mathrm{k}_{\mathrm{rg}}=$ Relative permeability to gas

$\mathrm{k}_{\mathrm{rw}}=$ Relative permeability to water

k' = Gas relative permeability coefficient

n' $=$ Gas relative permeability exponent

$\mathrm{m}^{\prime}=$ Water relative permeability exponent

$S_{\mathrm{w}}=$ Water saturation, fraction

$\mathrm{S}_{\mathrm{iw}}=$ Irreducible water saturation, fraction

$\mathrm{S}_{\mathrm{w}}{ }^{*}=$ Normalized water saturation

$\mathrm{S}_{\mathrm{wi}}=$ Initial cleat system water saturation (\%)

$\mathrm{w}_{\mathrm{i}}=$ Initial water volume in cleat system (Bbls)

$\mu=$ Viscosity (cp)

$\varphi=$ Porosity $(\%)$

$\mathrm{C}_{\mathrm{t}}=$ Total initial compressibility $\left(\mathrm{psi}^{-1}\right)$

$\mathrm{T}=$ Temperature $(\mathrm{R})$

$\mathrm{P}_{\mathrm{p}}$ or $\mathrm{P}_{\mathrm{c}}=$ Critical desorption pressure (psia)

$\mathrm{s}_{\mathrm{CA}}=$ Shape related pseudo-skin factor

$c^{\prime}=$ Shape factor conversion constant

$\mathrm{P}_{\mathrm{wf}}=$ Flowing bottom hole pressure (psia)

$\mathrm{Z}=\mathrm{z}$-factor

$\mathrm{s}=$ Skin factor

$\mathrm{r}_{\mathrm{e}}=$ Drainage radius $(\mathrm{ft})$

$\mathrm{r}_{\mathrm{w}}=$ Wellbore radius $(\mathrm{ft})$

$\mathrm{r}_{\mathrm{wD}}=$ Dimensionless wellbore radius 


\section{REFERENCES}

1. Aminian, K., Ameri, S. Journal of Natural Gas Science and Engineering. Predicting Production Performance of CBM Reservoirs. Elsevier B.V. 2009.

2. Aminian, K., Ameri, S., Bhavsar, A.B., Lakshminarayanan, S. "Type Curves for Production Prediction and Evaluation of Coalbed Methane Reservoirs", SPE 97957 (2005).

3. "Coalbed Methane-Homepage, USGS-ERP." About ERP - Central, USGS: Energy Resources Program. Web. 5 July 2011. 〈http://energy.cr.usgs.gov/oilgas/cbmethane/index.html>

4. “United States, Country Analysis Brief." U.S. Energy Information Administration. Independent Statistics \& Analysis. Web. 5 July 2011. $\langle$ http://www.eia.gov/countries/country-data.cfm?fips=US $>$.

5. "U.S. Coalbed Methane Proved Reserves, Reserves Changes, and Production." U.S. Energy Information Administration. Independent Statistics \& Analysis. Web. 5 July 2011. 〈http://www.eia.gov/dnav/ng/NG_ENR_COALBED_DCU_NUS_A.htm〉

6. Saulsberry, J.L., Schafer, P.S., Schraufnagel, R.A. (Eds.), A Guide to Coalbed Methane Reservoir Engineering. Chicago, IL: Gas Research Institute, 1996. Print.

7. Schlumberger Oilfield Glossary. Web. 4 July 2011. 〈http://www.glossary.oilfield.slb.com/>

8. "Directional Drilling Technology." U.S. Environmental Protection Agency. 27 June 2011. 〈 http://www.epa.gov/coalbed/docs/dir-drilling.pdf>

9. Drinkard, D. 2009. Predicting the Performance of Horizontal Wells in Unconventional Gas Reservoirs. Masters Thesis, West Virginia University, Morgantown, WV.

10. McElhiney, J.E., Koenig, R.A., and Schraufnagel, R.A.: "Evaluation of CBM Reserves Involves Different Techniques,” Oil \& Gas J. (October 1989) 87, No. 44, 63-72.

11. Bell, G.J., Jones, A.H., Morales, R.H., and Schraufnagel, R.A.: "Coalseam Hydraulic Fracture Propagation on a Laboratory Scale," Proc., SBM Symposium, Tuscaloosa, Alabama (April 1989) 417-425. 
12. Laubach, S.E., Marrett, R.A., Olson, J.E., Scott, A.R. "Characteristics and Origins of Coal Cleat: A Review," International Journal of Coal Geology 35. (1998) 175-207.

13. Aminian, K. "Coalbed Methane - Fundamental Concepts," Petroleum \& Natural Gas Engineering Department, West Virginia University, Morgantown, WV.

14. Joshi, S.D. Horizontal Well Technology. Tulsa, OK: PennWell Pub., 1991. Print. (49).

15. Aminian, K., Ameri, S., Sanchez, M., Garcia, A. and Bhavsar, A. "Type Curves for Coalbed Methane Production Prediction." SPE 91482 (2004).

16. Aminian, K., Ameri, S., Bhavsar, A. "Type Curves-Based Production Tool for CBM Prospects." SPE 111194 (2007).

17. Aminian, K., and S. Ameri. "Predicting Horizontal Well Production Performance Using Type Curves." SPE 19342(1989).

18. Eclipse Reservoir Engineering Software Manual. 2007. Schlumberger.

19. Aminian, K. Lecture 11. Advanced Natural Gas Engineering. Morgantown, WV: West Virginia University, Spring 2011.

20. Rogers, Ruby E., Muthukumarappan Ramurthy, Gary Dodvelt, and Mike Mullen. Coalbed Methane: Principles and Practices. $3^{\text {rd }}$ Edition. 2007, 20-21. 